\title{
Calpain-mediated cleavage of Atg5 switches autophagy to apoptosis
}

\author{
Shida Yousefi ${ }^{1}$, Remo Perozzo ${ }^{2}$, Inès Schmid ${ }^{1}$, Andrew Ziemiecki ${ }^{3}$, Thomas Schaffner ${ }^{4}$, Leonardo Scapozza ${ }^{2}$, \\ Thomas Brunner ${ }^{4}$ and Hans-Uwe Simon ${ }^{1,5}$
}

\begin{abstract}
Autophagy-related gene (Atg) $\mathbf{5}$ is a gene product required for the formation of autophagosomes. Here, we report that Atg5, in addition to the promotion of autophagy, enhances susceptibility towards apoptotic stimuli. Enforced expression of Atg5-sensitized tumour cells to anticancer drug treatment both in vitro and in vivo. In contrast, silencing the $\mathbf{A t g} 5$ gene with short interfering RNA (siRNA) resulted in partial resistance to chemotherapy. Apoptosis was associated with calpain-mediated Atg5 cleavage, resulting in an amino-terminal cleavage product with a relative molecular mass of 24,000 (M 24K). Atg5 cleavage was observed independent of the cell type and the apoptotic stimulus, suggesting that calpain activation and Atg5 cleavage are general phenomena in apoptotic cells. Truncated Atg5 translocated from the cytosol to mitochondria, associated with the anti-apoptotic molecule $\mathrm{Bcl}-\mathrm{x}_{\mathrm{L}}$ and triggered cytochrome c release and caspase activation. Taken together, calpain-mediated Atg5 cleavage provokes apoptotic cell death, therefore, represents a molecular link between autophagy and apoptosis - a finding with potential importance for clinical anticancer therapies.
\end{abstract}

Autophagy is a highly conserved process that occurs in yeast, plants and in mammalian cells. By means of autophagy, the cell keeps a constant balance between biosynthetic and catabolic processes, which also include the degradation of entire organelles. A portion of the cytoplasm is sequestered in an autophagosome and its contents are degraded on fusion with lysosomes ${ }^{1,2}$. Although autophagy promotes a cell-survival response ${ }^{3}$, morphological features of autophagy have also been observed in dying cells, where caspases (key enzymes in the process of apoptosis) were suppressed or not sufficiently activated. Therefore, autophagic cell death has been considered as a "fail-safe" mechanism under conditions in which apoptosis does not work ${ }^{4,5}$. Thus, a switch from apoptosis to autophagic cell death can occur. However, whether autophagy could promote apoptosis was not known.
The process of autophagosome formation is regulated by several autophagy genes (Atgs) $)^{1,2}$. Atg5- (ref. 6) or Atg6- (also known as Beclin$1)^{7,8}$ deficient mouse embryonic stem cells contain decreased numbers of autophagic vesicles, suggesting that at least some Atgs are essential for autophagy. We were interested in the effect of elevating Atg5 levels in cells and used two techniques for this purpose: first, HeLa cells were stably transfected with the GFP-tagged full-length human Atg5 (NCBI; accession number, 12803724), GFP-tagged cytochrome $c^{9}$, GFP-tagged microtubule-associated protein light chain (LC3, Atg8) or no insert. Second, Jurkat cells received Atg5 using lentiviral gene transfer. As control, the same vector with a GFP CDNA insert was used. In both systems, isolated exogenous Atg5 gene transfer resulted in cells exhibiting signs of increased autophagy (see Supplementary Information, Fig. S1).

We next investigated whether elevated Atg5 levels and subsequent increased autophagic activity were associated with changes in the susceptibility of cells to undergo death receptor-mediated or stress-mediated death. Compared with GFP-transfected (or untransfected) cells, an increased susceptibility to undergo death was observed in cells with enforced expression of Atg5. Atg5 sensitized cells to CD95-, ceramide- and anticancer drug- (etoposide and doxorubicin) mediated cell death, independent of the cell type. As an additional control, LC3 was overexpressed in HeLa cells and no increased susceptibility to death was observed (Fig. 1a). Increased Atg5 levels were also associated with increased caspase-3 activity after CD95 stimulation of HeLa cells, as well as with increased apoptotic morphology and phosphatidylinositol redistribution within the plasma membrane in anti-CD95 antibody and staurosporine treated Jurkat cells, suggesting that the type of death was apoptosis (Fig. 1b, c).

To further understand the requirement for Atg5 in induction of apoptosis, Atg5 levels were reduced using short interfering RNA (siRNA; Fig. 1d). Atg5-deficient HeLa and breast cancer MDA-MA-231 cells exhibited markedly reduced sensitivity towards the cytotoxic agents staurosporine and doxorubicin, respectively. It should be noted, however, that Atg5-deficient cells die in long-term cultures (5-7 days), possibly due to insufficient removal of defective cell organelles that may 
a
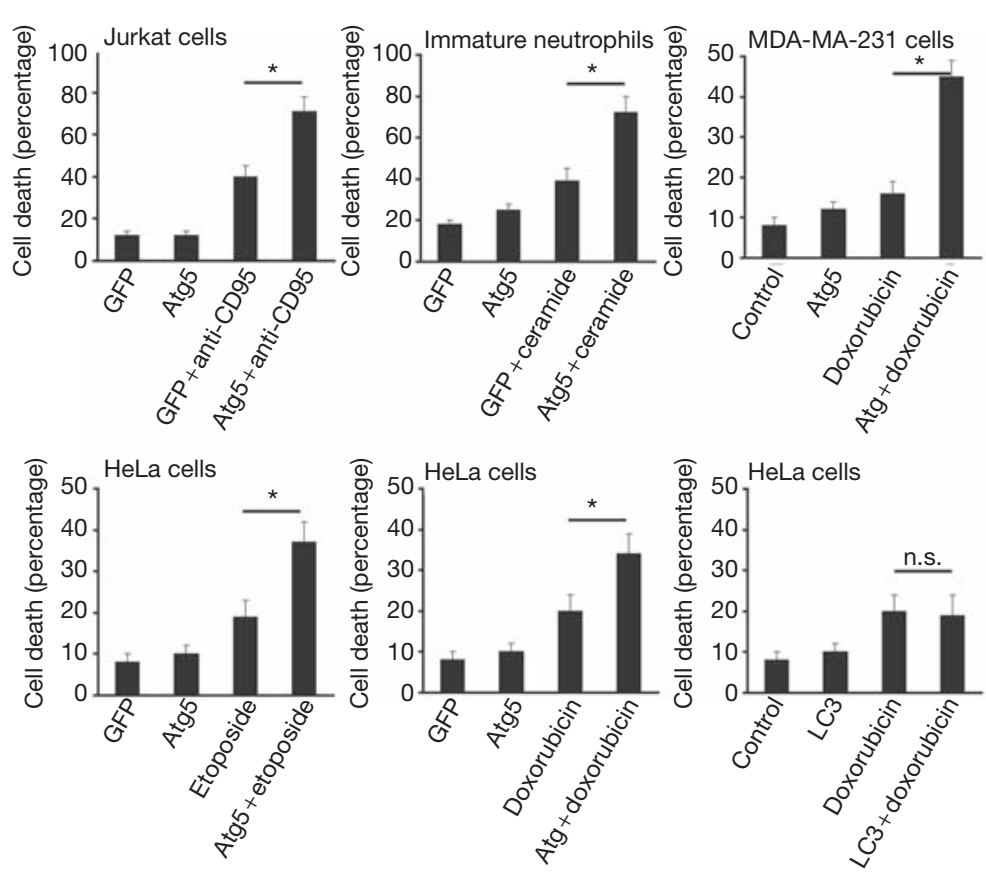

b

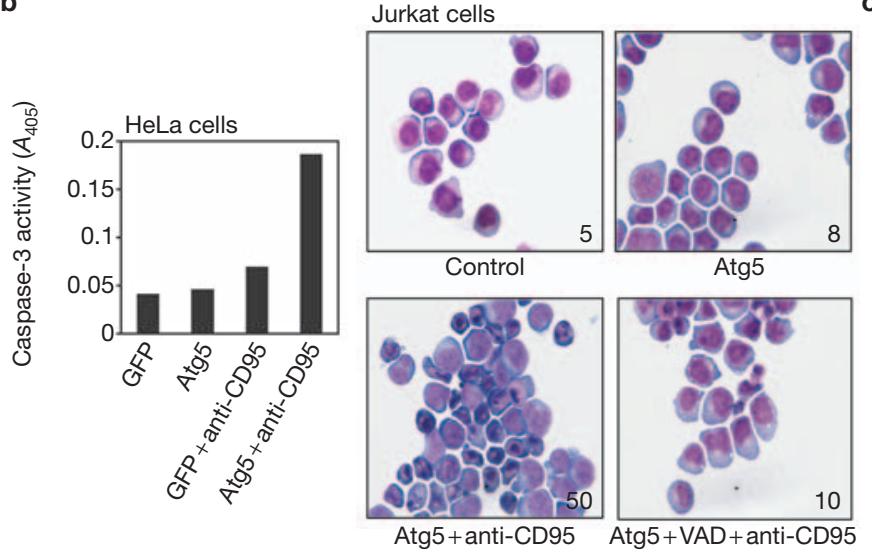

C Jurkat cells

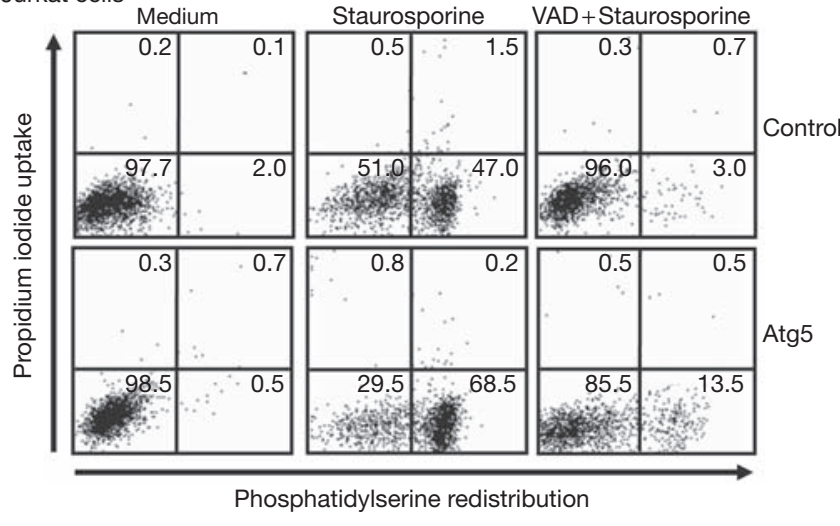

d
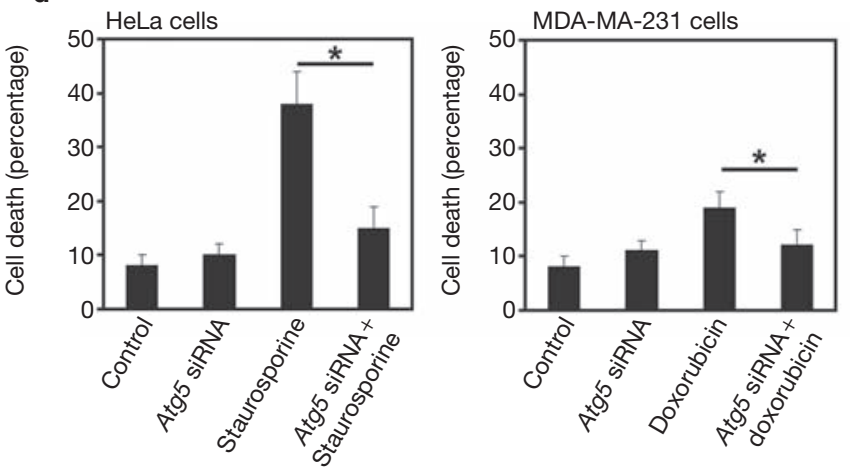

HeLa cells

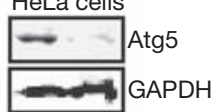

MDA-MA-231 cells

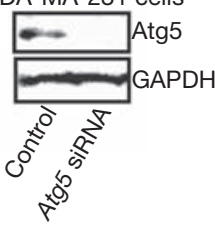

Figure 1 Atg5 regulates cytotoxicity of death triggers. (a) Cell death was analysed after the activation of death pathways in the presence and absence of enforced Atg5 expression (18 $\mathrm{h}$ cultures). Values are means \pm s.e.m. of three independent experiments. (b) The cell death regulated by Atg5 is apoptosis. All data presented are from $5 \mathrm{~h}$ cultures. Caspase-3-like activity analysed in HeLa cells (graph). Morphology of J urkat cells is also shown. The numbers in the lower right corner indicate the percentage of cell death, which was determined in parallel experiments using flow cytometry. (c) Staurosporine induced redistribution of phosphatidylserine was enhanced in Atg5 overexpressing J urkat cells and blocked by z-VAD-fmk. Numbers indicate the results of the quantitative analysis (percentage) of each dot blot. (d) Reduction of drug-induced cell death by silencing of Atg5. Values are means \pm s.e.m. of three independent experiments (18 $\mathrm{h}$ cultures). The effects of the Atg5 siRNA on Atg5 and GAPDH levels were analysed by immunoblotting. The asterisks indicate $P<0.05$. n.s., no significant difference. 
accumulate in cells with reduced autophagic activity ${ }^{3}$. In addition to these in vitro findings, we also obtained evidence for an apoptosis-sensitizing role forAtg5 in vivo (see Supplementary Information, Fig. S2).

To test the hypothesis that Atg5 has a role in apoptosis pathways, the model of spontaneous neutrophil apoptosis ${ }^{10}$ was used in initial experiments. Interestingly, an additional anti-Atg5-reactive molecule with an $M_{\mathrm{r}}$ of $24 \mathrm{~K}$ was detected in blood neutrophils from healthy donors that had been cultured in the absence of survival factors for $7 \mathrm{~h}$. In contrast, in the presence of the survival factor GM-CSF, the $24 \mathrm{~K}$ protein was not detected within this time period. Moreover, when the $24 \mathrm{~K}$ form appeared, full-length $33 \mathrm{~K}$ Atg5 was markedly reduced. In $24 \mathrm{~h}$ neutrophil cultures, the anti-Atg 5 antibody recognized the $24 \mathrm{~K}$ protein only and the $33 \mathrm{~K}$ protein was no longer detected (Fig. 2a). Next, Jurkat cells were stimulated with an anti-CD95 antibody known to induce apoptosis in these cells. In this model, the $24 \mathrm{~K}$ anti-Atg5-reactive molecule was rapidly detected (after $3 \mathrm{~h}$ stimulation) and its presence seemed to increase over time (Fig. 2b).

Other apoptosis triggers and cell types were also used. For instance, apoptosis was induced by staurosporine in Jurkat, HL-60 and EOL cells. Within $5 \mathrm{~h}$ of apoptosis induction, the $24 \mathrm{~K}$ protein, which was associated with caspase- 3 cleavage, was detected by immunoblotting (see Supplementary Information, Fig. S3a). In addition, antiCD95 treatment for $5 \mathrm{~h}$ was associated with the appearance of the $24 \mathrm{~K}$ protein in eosinophils and this was accompanied by cleavage of poly(ADP-ribose)polymerase (PARP), suggesting increased caspase3 activity in these cells (see Supplementary Information, Fig. S3b). Cycloheximide (CHX) or actinomycin D treatment caused, similarly to CD95 activation, the appearance of $24 \mathrm{~K}$ Atg 5 in Jurkat cells, making it unlikely that the molecule is newly synthesized during the process of apoptosis (Fig. 2b). These data suggest that 33K Atg 5 might be a target of one or more proteases that are activated during apoptosis, consistently resulting in a $24 \mathrm{~K}$ fragment of Atg5, independent of the apoptotic stimulus or the type of cell.

To obtain direct evidence for the Atg5 cleaving protease in apoptotic cells, a cell-free system, in which functionally active caspases, cathepsins or calpains were incubated with in vitro translated ${ }^{35} \mathrm{~S}$-labelled fulllength Atg5, was used. Several effector and initiator caspases (Fig. 3a), in addition to the cathepsins $\mathrm{B}$ and $\mathrm{D}$ (Fig. 3b), were unable to process Atg5. However, Atg5 was cleaved by both calpain-1 and calpain-2 to a $24 \mathrm{~K}$ fragment and this cleavage was blocked by three different calpain inhibitors (Fig. 3c). To identify the calpain cleavage site in Atg5, recombinant Atg5 was digested with calpain and the products were sequenced by Edman degradation. The relative molecular mass of truncated Atg5, determined by mass spectrometry after HPLC selection, was $23.447 \mathrm{~K}$ (Fig. 3d). Cleavage of Atg5 occurred at Thr 193, suggesting that the $24 \mathrm{~K}$ form of Atg5 represents an N-terminal fragment of the protein (Fig. 3e). An Atg5 molecule carrying a six-amino-acid deletion surrounding the cleavage site (Atg $5^{\Delta 191-196}$ ) that was calpain-resistant was generated (Fig. 3f).

To examine whether inhibition of calpains blocks Atg5 cleavage in intact cells undergoing apoptosis, blood neutrophils were incubated in the presence and absence of the calpain inhibitor ALLN, which inhibited both apoptosis (data not shown) and the occurrence of $24 \mathrm{~K}$ Atg5 in untreated and anti-CD95-treated neutrophils (7 h cultures). Similarly, cleavage of Bax, which is a target of calpain ${ }^{11,12}$, was blocked with ALLN, indicating successful calpain inhibition. In contrast with Atg5 and Bax, a

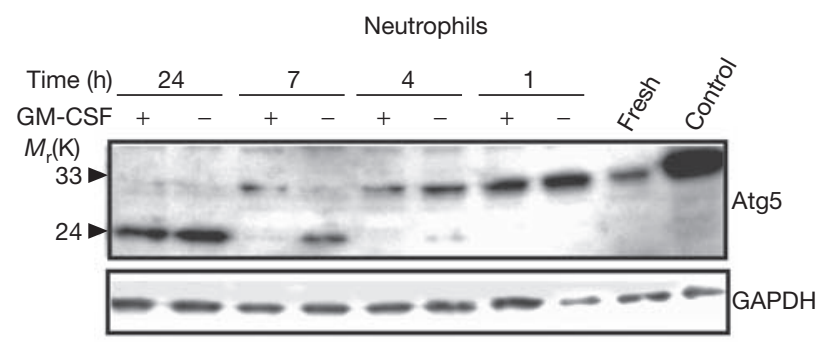

b

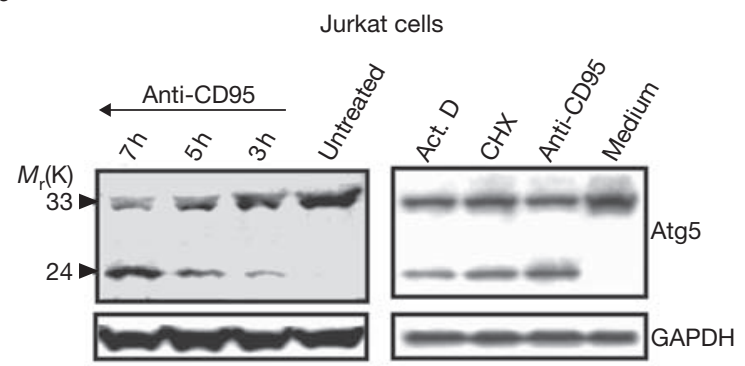

Figure 2 Apoptosis is associated with Atg5 cleavage as assessed by immunoblotting. (a) Spontaneous neutrophil apoptosis. Apoptosis was associated with the appearance of a $24 \mathrm{~K}$ anti-Atg5-reactive protein. $33 \mathrm{~K}$ Atg5 disappeared during apoptosis in a time-dependent manner. HeLa cells overexpressing Atg5 served as positive control. (b) Anti-CD95-induced apoptosis of J urkat cells. Apoptosis was associated with the appearance of a $24 \mathrm{~K}$ anti-Atg5-reactive protein and a reduction of $33 \mathrm{~K}$ Atg5 in a timedependent manner. The $24 \mathrm{~K}$ anti-Atg5-reactive protein was also visible in J urkat cells after treatment with actinomycin D (Act. D) or cycloheximide ( $\mathrm{CHX} ; 5 \mathrm{~h}$ treatment in both cases). GAPDH expression indicates equal loading in each panel. All immmunoblots are representative of at least three independent experiments.

Atg6 (refs 7, 8) did not seem to be a target of proteases in this system (Fig. 3g). The importance of calpain for Atg5 cleavage in intact cells was also demonstrated using HeLa cells lacking detectable amounts of the common $28 \mathrm{~K}$ calpain subunit ${ }^{13}$. Calpain-deficient HeLa cells were generated using specific siRNA. In calpain-deficient cells, staurosporine treatment was not associated with Atg5 cleavage, confirming that calpain is indeed the protease responsible (Fig. $3 \mathrm{~h}$ ).

As enzymatic inhibition of calpain blocked neutrophil apoptosis ${ }^{12}$, we wanted to determine whether calpain-mediated cleavage of Atg5 was critical for apoptosis. Overexpression of Atg $5^{\Delta 191-196}$ in Atg5-deficient HeLa cells (treated with Atg5 siRNA, see Fig. 1d), did not result in increased sensitivity to staurosporine (Fig. 3i), suggesting that calpainmediated cleavage of Atg5 is a critical pro-apoptotic event in at least some forms of apoptosis.

To examine the possibility that the $24 \mathrm{~K} \mathrm{~N}$-terminal cleavage product of Atg5 regulates apoptosis, it was transiently overexpressed in HeLa cells. In cells overexpressing the $24 \mathrm{~K}$ truncated form evidence for the induction of apoptosis was observed (nuclear condensation), although less efficiently compared with Bax (Fig. 4a). In addition to nuclear condensation, $24 \mathrm{~K}$ Atg5-induced cell death was associated with cytochrome $c$ release into the cytosol, whereas, at least for a certain period of time, mitochondrial staining with Mitotracker orange was unchanged (Fig. 4b). The ability of $24 \mathrm{~K}$ Atg 5 to induce apoptosis was not a consequence of cell detachment because more than $50 \%$ of the apoptotic cells expressing truncated Atg5 were still adherent. 


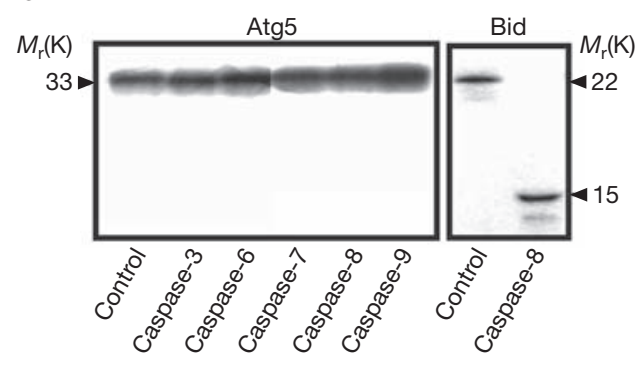

d

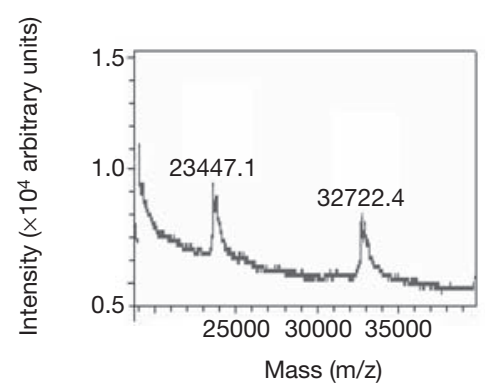

g

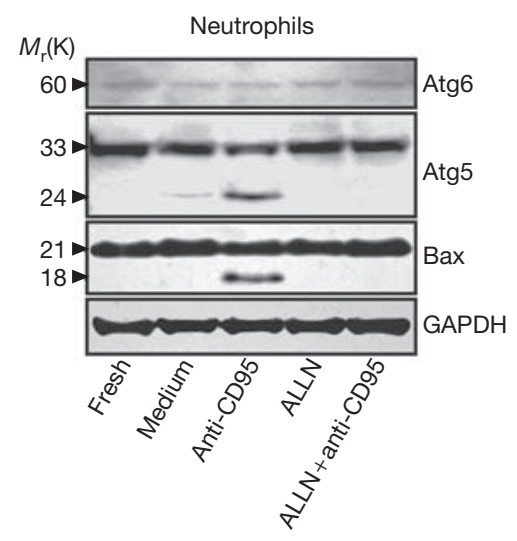

b

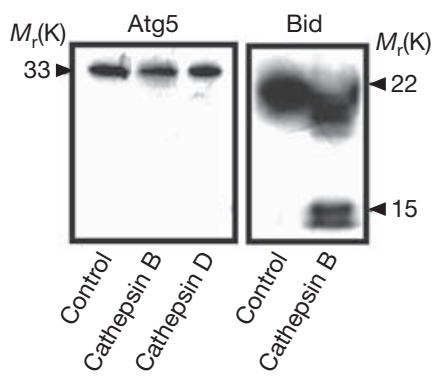

e

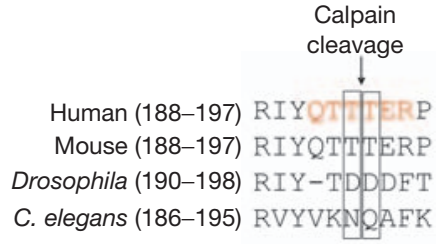

h

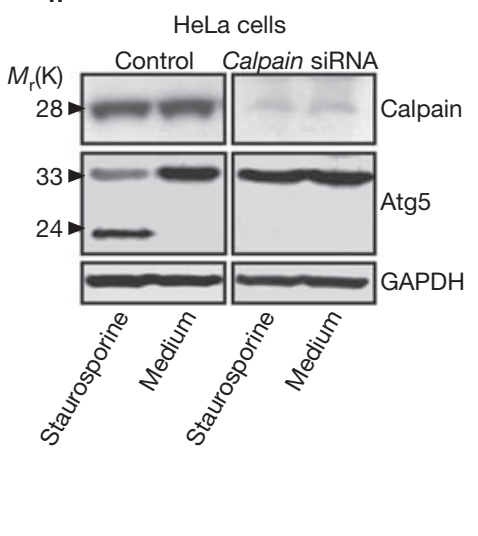

c

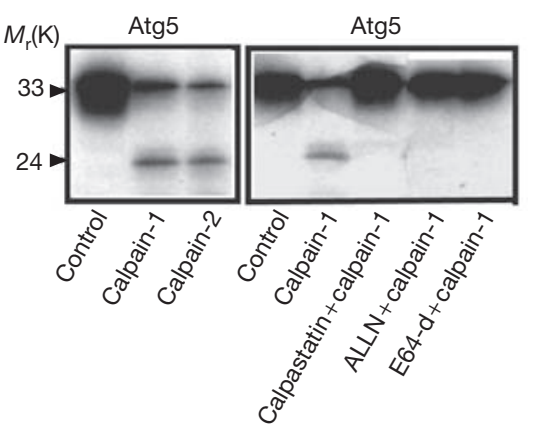

f

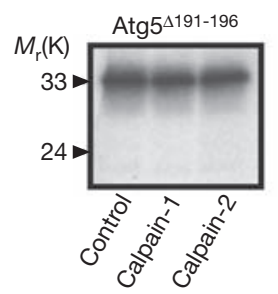

i

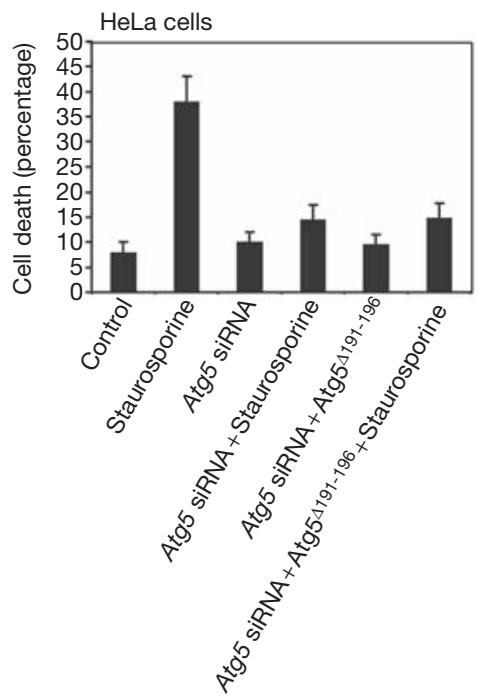

Figure 3 Atg5 is cleaved by calpain. (a) Caspases-3, $-6,-7,-8$ and -9 did not cleave ${ }^{35} \mathrm{~S}$-Atg5. To control the reaction conditions, ${ }^{35} \mathrm{~S}-\mathrm{Bid}$ was cleaved by caspase- 8 . The enzymatic activity of caspases-3, $-6,-7$ and -9 were controlled by incubating them together with lysates of J urkat cells and subsequent caspase- 3 immunoblotting experiments (data not shown). (b) Cathepsins B and D did not cleave ${ }^{35} \mathrm{~S}$-Atg5. To control the reaction conditions, ${ }^{35} \mathrm{~S}-\mathrm{Bid}$ was cleaved by cathepsin B. (c) Calpains-1 and -2 cleaved ${ }^{35} \mathrm{~S}$-Atg5. The calpain inhibitors calpastatin, ALLN and E64-d completely prevented calpain-mediated cleavage of ${ }^{35} \mathrm{~S}$-Atg5.

(d) Following calpain-mediated cleavage of recombinant Atg5 in vitro, the sample was fractionated by preparative reversed-phase HPLC and analysed by mass spectrometry. The exact relative molecular masses for full-length and truncated Atg5 are indicated. (e) Recombinant Atg5 was digested with calpain and the products sequenced by Edman degradation. Calpain cleaved Atg5 at Thr 193. Comparison of Atg5 sequences of

To further exclude the possibility that truncated Atg5 induces apoptosis as a consequence of cell rounding and detachment (anoikis), Jurkat cells were transfected with full-length and truncated Atg 5 using a lentiviral transfection system (Fig. 4c). Again, 24K Atg5 induced cell different species demonstrates the presence of the same calpain cleavage site in mice. The sequence alignment was perfromed with Clustal W using sequence data obtained from GenBank. The position of the six-amino-acid deletion causing calpain resistance is indicated in red. (f) A six-aminoacid deletion surrounding the cleavage site $\left({ }^{35} \mathrm{~S}-\mathrm{Atg} 5^{\Delta 191-196}\right)$ led to a loss of the calpain cleavage fragment. (g) Calpain inhibition by ALLN blocked both cleavage of Bax and Atg5 in spontaneous and Fas receptor-mediated apoptosis of neutrophils. In contrast, Atg6 did not show evidence for cleavage and its levels remained unchanged in this system. Results of $7 \mathrm{~h}$ cultures are shown. (h) Atg5 is not cleaved in apoptotic HeLa cells (5 h staurosporine treatment) lacking the small subunit of calpain, which was silenced by using specific siRNA. (i) Calpain resistant Atg5 $5^{\Delta 191-196}$ was unable to sensitize HeLa cells lacking endogeneous Atg5 (due to gene silencing, see Fig. 1c) to staurosporine-induced cell death. Values are means \pm s.e.m. of three independent experiments ( $18 \mathrm{~h}$ cultures).

death in a time-dependent manner, whereas full-length Atg5 had no significant effect compared with GFP-transfected cells. Morphological changes were again observed in the $24 \mathrm{~K}$ Atg 5 transfected cells, which were consistent with apoptosis (Fig. 4c). 
a

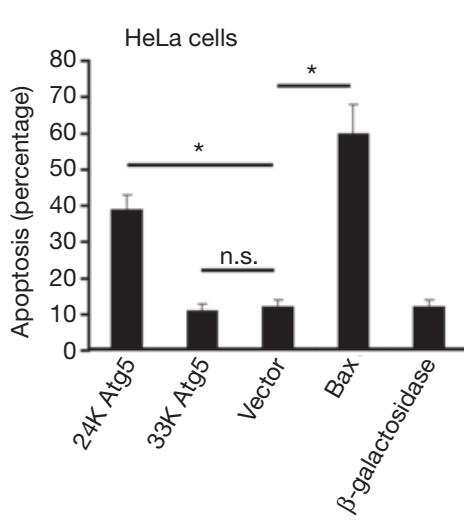

d

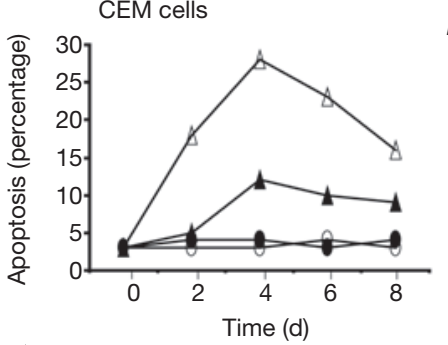

$\triangle 24 \mathrm{~K} A t g-B c / 2$

$\Delta 24 \mathrm{~K} \mathrm{Atg}+B \mathrm{Cl} 2$

O GFP $-B C l 2$

- $\mathrm{GFP}+B c / 2$
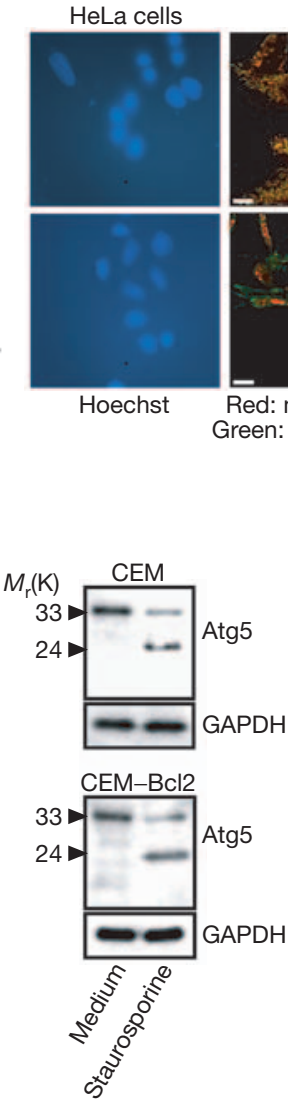

f

f Hela cells

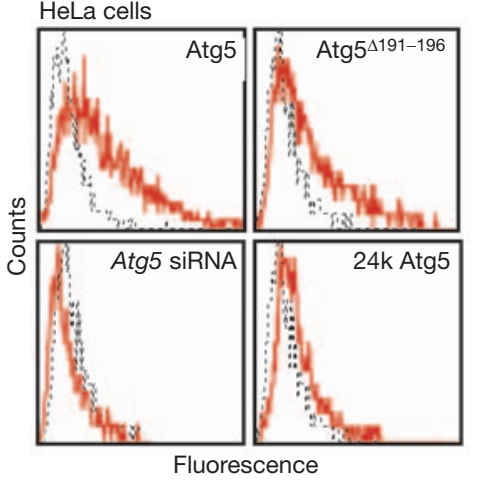

C

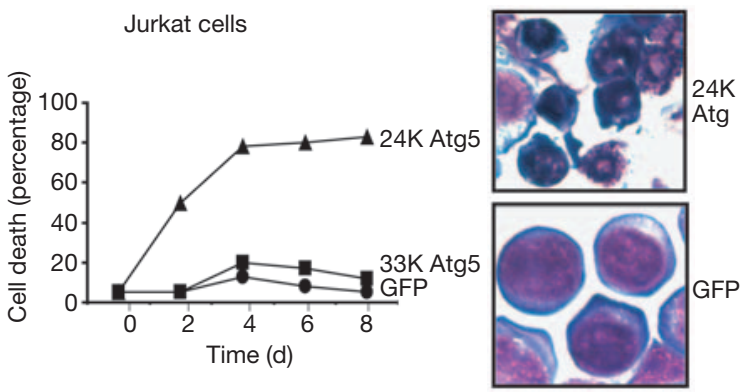

Figure 4 Enforced expression of truncated Atg5 induces apoptosis, which is blocked by BCl-2. (a) HeLa cells were transiently transfected with $24 \mathrm{~K}$ and $33 \mathrm{~K}$ Atg5 for $24 \mathrm{~h}$ and subsequently analysed by Hoechst staining. Values are means \pm s.e.m. of three independent experiments. Bax transfection was used as a positive control. (b) Representative images after Hoechst staining demonstrating nuclear fragmentation of HeLa cells that were transfected with $24 \mathrm{~K}$ Atg5 using lentiviral gene transfer for $24 \mathrm{~h}$. Quantitative analysis of these experiments is shown in a. Control and transfected cells were loaded with Mitotracker orange and subsequently processed for cytochrome c immunostaining. Enforced expression of 24K Atg5 resulted in cytochrome $\mathrm{c}$ release into the cytosol and apoptosis (nuclear condensation, cell shrinkage; approximately $80 \%$ of the cells). (c) J urkat cells were transfected with $24 \mathrm{~K}$ and $33 \mathrm{~K}$ Atg5 using lentiviral gene transfer. Cell death was observed as a consequence of enforced expression of truncated Atg5 within two days. Morphological analysis (Diff-Quik) is also shown and revealed that the type of death was apoptosis (nuclear condensation, cell shrinkage). (d) CEM cells

Overexpression of $24 \mathrm{~K}$ Atg5 in CEM cells also resulted in rapid DNA fragmentation. However, in the presence of high levels of $\mathrm{Bcl}$ 2 (ref. 14), transfection of truncated Atg5 had only little death activity (Fig. $4 \mathrm{~d}$ ). Interestingly, although $\mathrm{Bcl}$-2-expressing CEM cells were largely protected from staurosporine-induced apoptosis, endogenous Atg5 was equally cleaved in these cells compared with control cells (Fig. 4e). Therefore, cleavage of Atg5 is not necessarily associated with cell death and seems to occur within a pro-apoptotic pathway proximal to mitochondria.

To determine whether Atg5-mediated increased autophagy is required for increased susceptibility to apoptosis, HeLa cells with different levels of autophagic activity were examined. As expected, Atg5 siRNA treatment resulted in decreased autophagic activity and enforced Atg5 expression accelerated autophagy. Interestingly, calpainresistant Atg $5^{\Delta 191-196}$ also stimulated autophagy, suggesting that calpain that either lacked $\mathrm{BCl}-2$ or expressed high levels of $\mathrm{BCl}-2$ received truncated Atg5 or GFP by lentiviral gene transfer. In the absence of $\mathrm{BCl}-2$, induction of apoptosis as assessed by DNA fragmentation was observed due to enforced expression of truncated Atg5 within two days. Apoptosis was largely blocked in cells expressing high levels of $\mathrm{BCl}-2$. GFP transfection did not affect viability of the cells in this system. (e) Staurosporine-induced Atg5 cleavage ( $5 \mathrm{~h}$ treatment) in CEM cells independent of $\mathrm{BCl}-2$ expression. Blots were stripped and reprobed with anti-GAPDH antibody. (f) Detection of autophagic activity by staining of acidic vesicular organelles (VAOs, red) followed by flow cytometric analysis in genetically modified HeLa cells. That $24 \mathrm{~K}$ Atg5 did not induce autophagy was confirmed by transmission electron microscopy (data not shown). (g) Cell death after 24K Atg5 gene transfer in HeLa cells exhibiting different autophagic activities. Values are means $\pm \mathrm{s}$. e.m. of three independent experiments (lentiviral gene transfer for $24 \mathrm{~h}$ ). The asterisks indicate $P<0.05$. n.s., no significant difference. The scale bars represent $10 \mu \mathrm{M}$.

cleavage is not required for inducing autophagy. In contrast, overexpression of $24 \mathrm{~K}$ Atg5 did not induce autophagy (Fig. 4f). Transfection of the construct for $24 \mathrm{~K}$ Atg 5 in these different cells revealed that cell death occurs independently of autophagic activity (Fig. 4g). Therefore, the autophagic activity of Atg5 does not seem to be required for the apoptotic effect of truncated Atg5.

As $24 \mathrm{~K}$ Atg5 induced cytochrome $c$ release and apoptosis in different cell types not protected by high levels Bcl-2, we reasoned that truncated Atg5 would activate the mitochondrial death pathway and investigated whether Atg5 translocates to mitochondria when apoptosis was induced. Non-apoptotic and anti-CD95 antibody-stimulated HeLa cells were analysed by immunofluorescence staining and confocal microscopy. In non-apoptotic cells, Atg5 was observed in the cytosol and exhibited diffuse cellular staining with little mitochondrial localization detected. In contrast, after treatment with anti-CD95 
a

HeLa cells

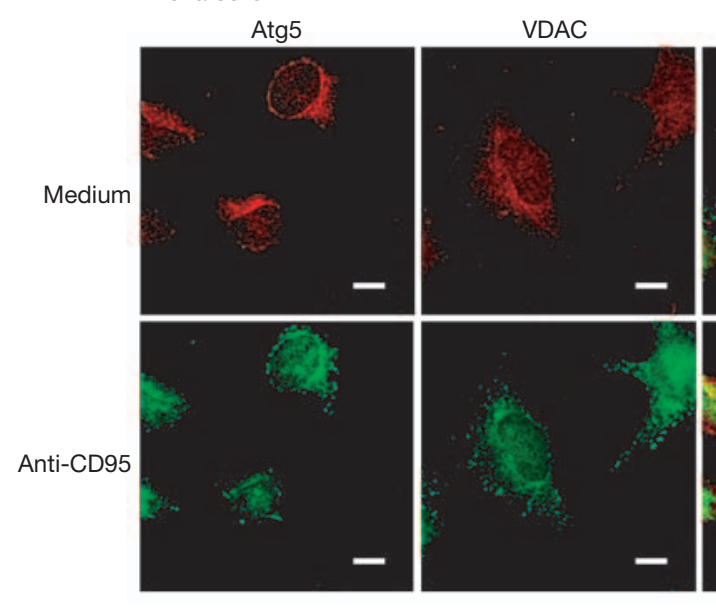

b

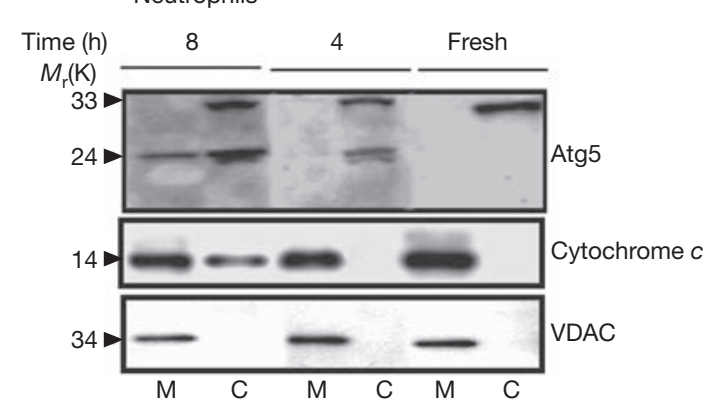

Atg5-VDAC

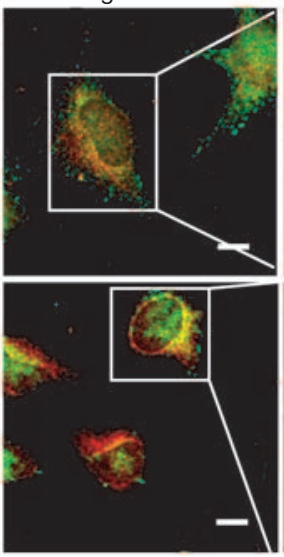

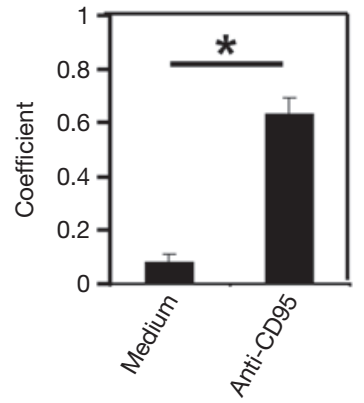

colocalization
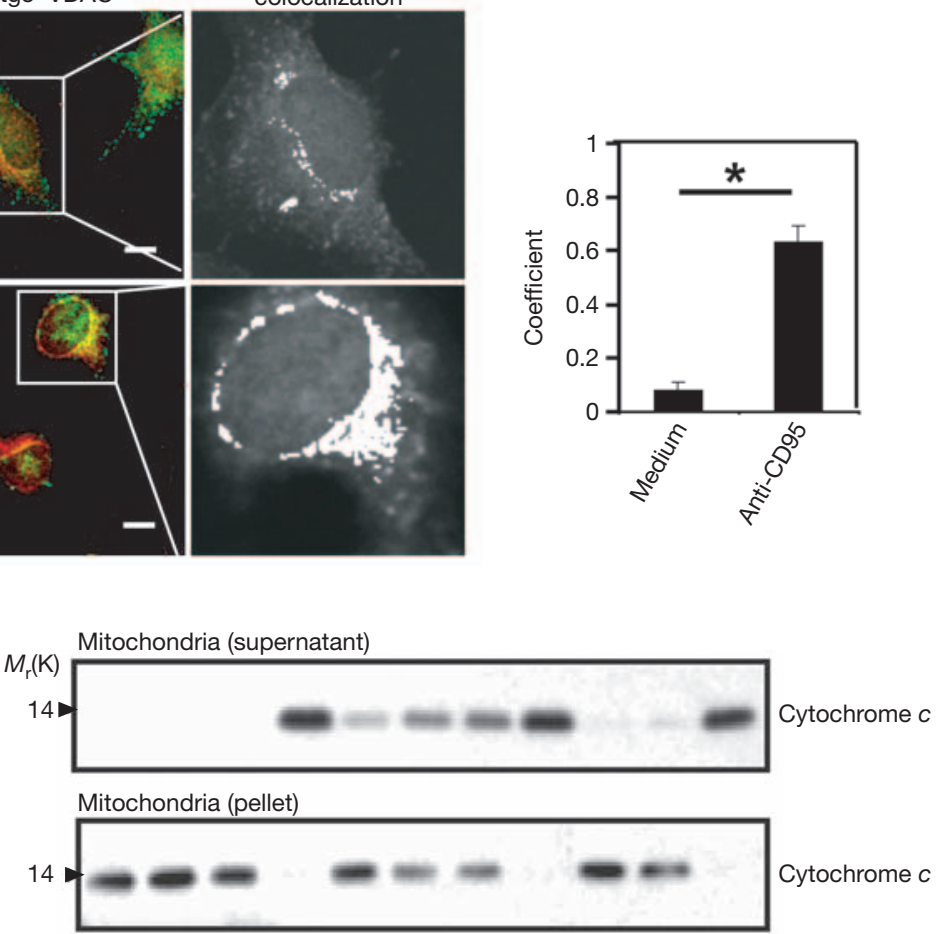

34

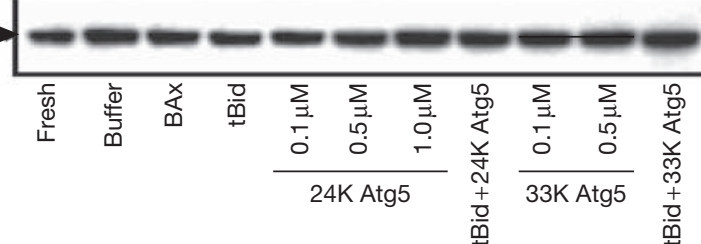

VDAC

d

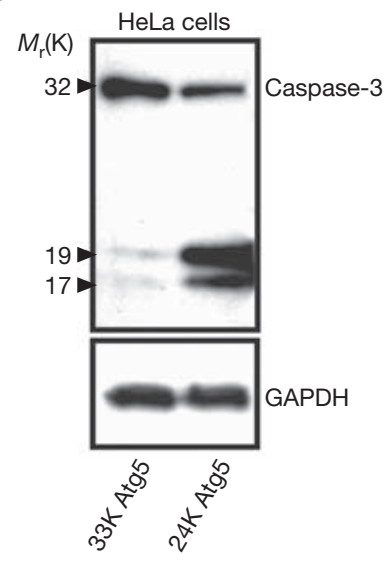

Jurkat cells

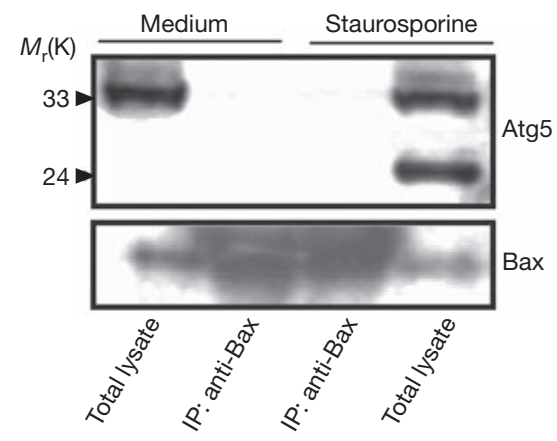

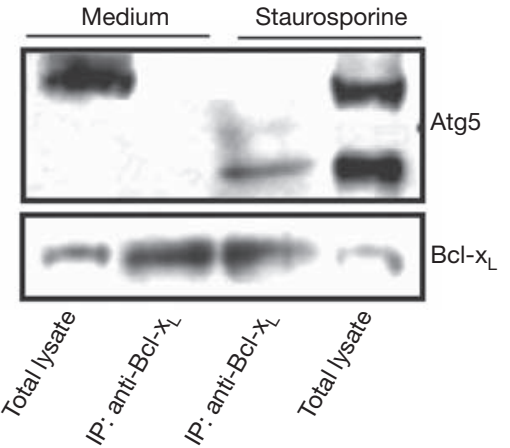

Figure 5 Truncated Atg5 translocates to mitochondria, binds to $\mathrm{BCl}-\mathrm{X}_{\mathrm{L}}$ but not Bax and releases cytochrome $c$ into the cytosol. (a) Confocal microscopy of HeLa cells were treated with anti-CD95 antibody for $5 \mathrm{~h}$ or left untreated. Cells were stained with anti-Atg5 and anti-VDAC antibodies. In untreated cells, there was only little evidence for colocalization of Atg5 and VDAC. In anti-CD95 antibody treated cells some of the Atg5 colocalized with VDAC. The images of colocalization were prepared using Imaris software. Numerical analysis was performed on 10 cells in each group and the correlation coefficient calculated. The error bars represent the s.e.m. (b) Subcellular fractionation of blood neutrophils that were left untreated to induce spontaneous apoptosis. After $4 \mathrm{~h}$ incubation, cleavage of Atg5 was evident and both full-length and truncated A tg5 were present in the cytosol. After $8 \mathrm{~h}$ incubation, some $24 \mathrm{~K}$ Atg5 but not full-length Atg5 was found in the mitochondrial fraction. Mitochondrial association of truncated Atg5 coincided with the release of cytochrome c into the cytosol. The same data were observed in staurosporine-induced apoptosis of J urkat cells (data not shown). C, cytosol; M, mitochondria. (c) Cytochrome c release assay. Truncated and full-length recombinant Atg5 were added to isolated mitochondria and incubated at $37^{\circ} \mathrm{C}$ for $1 \mathrm{~h}$. Supernatants and mitochondrial pellets were then analysed for cytochrome c by immunoblotting. Truncated Bid (tBid) was used as a positive control for mitochondrial permeabilization. Truncated Atg5 released cytochrome $\mathrm{c}$ in a concentration-dependent manner, indicating mitochondrial permeabilization. Full-length Atg5 had only little effect in this system. (d) HeLa cells were transfected with $24 \mathrm{~K}$ and $33 \mathrm{~K}$ Atg5 using lentiviral gene transfer for $24 \mathrm{~h}$ and analysed for caspase-3 cleavage. GAPDH expression demonstrates equal loading. (e) J urkat cells were treated with staurosporine for $5 \mathrm{~h}$ or left untreated. Staurosporine induced Atg5 cleavage and both full-length and truncated Atg5 were present in total lysates. Truncated but not full-length Atg5 was detected in $\mathrm{BCl}-\mathrm{x}_{\mathrm{L}}$ immunoprecipitates obtained from apoptotic J urkat cells. No evidence for physical interaction between Atg5 and Bax was obtained. The lower panels demonstrate that both $\mathrm{Bax}$ and $\mathrm{BCl}-\mathrm{X}$ were enriched following immunoprecipitation. The asterisk indicates $P<0.05$. The scale bars represent $10 \mu \mathrm{M}$. 
antibodies, colocalization of Atg5 and the mitochondrial marker VDAC was observed, suggesting that either full-length or truncated Atg5 (or both) translocated to mitochondria (Fig. 5a).

To identify the form of Atg5 translocating to mitochondria during apoptosis, we separated cytosol and membranes in neutrophils undergoing apoptosis and subsequently detected Atg 5 by immunoblotting. The $24 \mathrm{~K} \operatorname{Atg} 5$ fragment associated with neutrophil apoptosis was first visible in the cytosol and subsequently appeared in the mitochondrial fraction, giving rise to the possibility that truncated Atg5, but not full-length Atg5, translocates to mitochondria. In addition, the appearance of $24 \mathrm{~K}$ Atg 5 in the mitochondrial fraction correlated with the detection of cytochrome $c$ in the cytosol (Fig. 5b).

To demonstrate that cytochrome $c$ is released as a consequence of a physical interaction between mitochondria and truncated 24K Atg5, isolated mouse liver mitochondria were incubated with recombinant full-length $33 \mathrm{~K}$ and truncated $24 \mathrm{~K}$ Atg5. Truncated Bid (tBid) is know to permeabilize mitochondria and was therefore used as a positive control. The $24 \mathrm{~K}$ form of Atg5 released cytochrome $c$ from mitochondria in a concentration-dependent manner and similarly to tBid (Fig. 5c). In contrast, full-length Atg5 released only little and almost undetectable amounts of cytochrome $c$ in this system. We also observed that the $24 \mathrm{~K}$ Atg5-mediated cytochrome $c$ release was associated with caspase-3 cleavage (Fig. 5d) and that the induced apoptosis can be blocked by the pan-caspase inhibitor, $\mathrm{z}$-VAD-fmk (data not shown). Together, these data suggest that the $24 \mathrm{~K}$ Atg5 fragment translocates to mitochondria and releases, either alone or in concert with other pro-apoptotic proteins, cytochrome $c$ to activate effector caspases.

To investigate whether truncated Atg5 may trigger cytochrome $c$ release by binding to members of the Bcl-2 family, an immunoprecipitation-immunoblot analysis was performed in whole-cell lysates. In both non-apoptotic and staurosporine-treated ( $5 \mathrm{~h}$ ) apoptotic Jurkat cells, full-length and truncated Atg5 did not seem to bind to Bax. In contrast, truncated Atg5, but not full-length Atg5, associated with Bcl- $\mathrm{x}_{\mathrm{L}}$ in apoptotic, but not in non-apoptotic, Jurkat cells (Fig. 5e) - a finding that was confirmed in apoptotic HeLa cells and neutrophils (data not shown).

Thus, the possibility exists that truncated Atg 5 promotes apoptosis by blocking the function of $\mathrm{Bcl}-\mathrm{x}_{\mathrm{L}}$ leading to Bax activation. This type of mechanism has been described for some BH3-only proteins that inactivate $\mathrm{Bcl}-2$-like survival proteins, which keep cells alive by inactivating Bax-Bak-like proteins ${ }^{15}$. However, it is not currently known whether binding of truncated Atg5 to Bcl- $\mathrm{x}_{\mathrm{L}}$ leads to $\mathrm{Bcl}-\mathrm{x}_{\mathrm{L}}$ inactivation and subsequent activation of Bax-Baklike molecules. Clearly, further work is required to understand the precise mechanism of the apoptosis-promoting effect of truncated Atg5. Nevertheless, Atg5-induced death was blocked by high levels of expression of $\mathrm{Bcl}-2$, supporting the hypothesis that truncated Atg5 targets mitochondria to release cytochrome $c$ and perhaps other pro-apoptotic factors.

Direct death signalling through translocation to mitochondria has previously been reported for proteins not belonging to the Bcl-2 family. For instance, recent studies demonstrated that a fraction of p53 translocates to mitochondria during stress-induced apoptosis, but not during growth arrest ${ }^{16,17}$. Similarly, no Atg 5 cleavage and translocation was observed in non-proliferating viable cells. The mechanism of p53mediated cytochrome $c$ release involved, at least in part, the disruption of the Bax-Bcl- $\mathrm{x}_{\mathrm{L}}{ }^{18}$ and/or the Bak-Mcl-1 complex ${ }^{19}$. Interestingly, transcription factor 3 (ref. 20), the Peutz-Jegher gene product LKB1 (ref. 21) and cofilin ${ }^{22}$ have also been shown to translocate to mitochondria and to subsequently promote apoptosis.

The ubiquitous expression of both calpain and Atg5 suggests that the new intracellular death pathway described here is important for multiple cells in different lineages. Calpain has previously been described as being an upstream regulator of apoptosis that targets Bax, generating an $M_{\mathrm{r}} 18 \mathrm{~K}$ fragment with increased pro-apoptotic activity ${ }^{11,12}$. Our observation of Atg 5 cleavage in cells, independent of the apoptotic trigger, suggests that calpain activation is a general phenomenon associated with apoptosis. Moreover, at least in certain circumstances (for instance in drug-induced apoptosis), cleavage of Atg5 by calpain represents a critical pro-apoptotic event. Further work is required to understand how calpain is activated in the process of apoptosis.

In summary, we provide mechanistic insight into the functional roles of both calpain and Atg5 in regulating pro-apoptotic signalling pathways and report that cells with elevated amounts of Atg5 exhibit increased autophagic activity and increased likelihood to undergo apoptosis compared with normal cells. However, the increased death susceptibility mediated by Atg 5 does not seem to be dependent on its capacity to induce autophagy. When cell death is inducted, Atg5 is used to promote apoptosis, which is mitochondria and caspasedependent. The data reported here have obvious ramifications for the treatment of cancer.

\section{METHODS}

Cells. Isolations of blood neutrophils ${ }^{23}$, blood eosinophils ${ }^{24}$ and bone marrowderived immature neutrophils ${ }^{25,26}$ were performed as previously described. Please see Supplementary Information, Methods for information on cell lines.

Cell cultures. Cells were cultured at $1 \times 10^{6}$ per $\mathrm{ml}$ and, where indicated, treated with GM-CSF $\left(25 \mathrm{ng} \mathrm{ml}^{-1}\right)$, ALLN $(10 \mu \mathrm{M})$, anti-CD95 receptor monoclonal antibody $\left(1 \mu \mathrm{g} \mathrm{ml}^{-1} \mathrm{CH} 11\right.$; MBL International Corp., Woburn, MA), staurosporine $(0.5 \mu \mathrm{M})$, etoposide $(0.5 \mu \mathrm{M}$; Bristol-Myers Squibb AG, Baar, Switzerland) and doxorubicin $(0.5 \mu \mathrm{M}$; Sigma, Buchs, Switzerland) for the indicated times.

Gel electrophoresis and immunoblotting. Cells $\left(1-2.5 \times 10^{6}\right)$ were washed with PBS, lysed with modified RIPA-buffer ( $0.5 \%$ sodium deoxycholate, $1 \%$ NP40 in PBS) supplemented with a protease inhibitor-cocktail (Sigma) and $100 \mu \mathrm{M}$ PMSF with frequent vortexing on ice for $30 \mathrm{~min}$. Alternatively, cells were lysed with $2 \times$ loading buffer (Invitrogen, Paisley, UK) and sonicated. After a $10 \mathrm{~min}$ centrifugation step to remove insoluble particles, equal amounts of the cell lysates were loaded on NuPagegels. Separated proteins were electrotransferred onto PVDF membranes (Immobilion-P; Millipore, Bedford, MA). The filters were incubated with primary antibodies at $4{ }^{\circ} \mathrm{C}$ overnight in TBS, $0.1 \%$ Tween$20,3 \%$ non-fat dry milk. The primary antibodies were: polyclonal anti-Atg5 (1:5000), polyclonal anti-caspase-3 (1:1000; BD Biosciences, Erembodegem, Belgium), polyclonal anti-PARP (1:1000; Cell Signaling, Danvers, MA), polyclonal anti-Beclin-1 (1:1000; Cell Signalling), monoclonal anti-GFP (1:5000; Becton Dickinson Biosciences), monoclonal anti-calpain (small subunit, clone P1, 1/1000; Chemicon International, Inc. Chandlers Ford, UK) and monoclonal anti-GAPDH (1/5000; Chemicon International). Filters were washed in TBS, $0.1 \%$ Tween-20 for $30 \mathrm{~min}$ and incubated with the appropriate HRP-conjugated secondary antibody (Amersham, Dübendorf, Switzerland) in TBS, 0.1\% Tween-20, 5\% non-fat dry milk for $1 \mathrm{~h}$. Filters were developed by an ECL-technique (ECL-Kit, Amersham). In some experiments, immunoprecipitation was performed before immunoblotting (see Supplementary Information, Methods).

Subcellular fractionation. Freshly purified neutrophils were cultured for the indicated times, washed with cold PBS and digitonin-permeabilized essentially as previously described ${ }^{27}$. Equal amounts of proteins supplemented with NuPAGEloading buffer were loaded on $12 \%$ NuPAGE gels and subsequently transferred to PVDF membranes. Filters were incubated with polyclonal anti-Atg5 (1:5000), 
monoclonal anti-cytochrome $c$ (1:5000; Becton Dickinson Biosciences) and monoclonal anti-VDAC (1:5000; Calbiochem-Novabiochem Corp., La Jolla, CA) antibodies.

Determination of cell death and apoptosis. Cell death was assessed by uptake of $1 \mu \mathrm{M}$ ethidium bromide and flow cytometric analysis (FACS Calibur; Becton Dickinson, Heidelberg, Germany) ${ }^{28}$. To determine whether cell death was apoptosis, morphologic analysis using $10 \mu \mathrm{m}$ Hoechst (Molecular Probes, Leiden, The Netherlands) or Diff-Quik (Baxter, Düdingen, Switzerland), as well as Annexin V staining $^{29}$ and DNA fragmentation ${ }^{12,29}$ assays were performed. Caspase-3 activity was measured as enzymatic conversion of the colorimetric substrate Ac-DEVDpNA at $405 \mathrm{~nm}$ according to the manufacturer's instructions (QuantiZyme caspase-3 cellular activity assay kit; Biomol International, Exeter, UK).

Determination of autophagic activity. Vacuolization and double membrane structures were analysed by transmission electron microscopy. Induction of autophagy was further demonstrated using GFP-LC3 (kind gift from T. Yoshimori, Osaka University, Osaka, Japan), which was expressed in HeLa cells. Cells were cultured under the indicated conditions and analysed by confocal microscopy and immunoblotting. The development of acidic vesicular organelles (AVOs), which correlates with autophagic activity, was also measured using the lysosomotropic fluorescent dye acridine orange and flow cytometry ${ }^{30}$.

In vitro protease cleavage assay. To directly determine which intracellular protease cleaved Atg5 ${ }^{35} \mathrm{~S}$-Atg 5 or ${ }^{35} \mathrm{~S}$-Atg $5^{\Delta 191-196}$ were incubated (see below) with $4 \mathrm{U}$ caspase- 3 , $4 \mathrm{U}$ caspase-8, $0.5 \mathrm{U}$ calpain-1, $0.5 \mathrm{U}$ calpain-2, $0.1 \mathrm{U}$ cathepsin $B$ and $0.1 \mathrm{U}$ cathepsin D in caspase buffer (50 mM HEPES at pH 7.4, $100 \mathrm{mM}$ $\mathrm{NaCl}, 10 \%$ sucrose, $1 \mathrm{mM}$ EDTA, $0.1 \%$ CHAPS, $10 \mathrm{mM}$ DTT), cathepsin buffer (340 mM NaOAc, $60 \mathrm{mM}$ acetic acid, $4 \mathrm{mM}$ EDTA, $8 \mathrm{mM}$ DTT, 0.1\% CHAPS at pH 5.5) and calpain buffer (20 mM PIPES, $100 \mathrm{mM} \mathrm{NaCl}, 10 \mathrm{mM} \mathrm{DTT}, 0.1 \%$ CHAPS, $10 \%$ sucrose, $1 \mathrm{mM} \mathrm{CaCl}_{2}$ at $\mathrm{pH} 7.2$ ), respectively, at $37^{\circ} \mathrm{C}$ for $1 \mathrm{~h}$. ${ }^{35} \mathrm{~S}$-Bid served as positive control in the caspase and cathepsin experiments. The specificity of calpain action was controlled by using the following calpain inhibitors: E64-d (50 $\mu \mathrm{M})$, calpastatin-derived peptide (10 $\mu \mathrm{M})$, ALLN $(10 \mu \mathrm{M})$. The reaction was stopped by adding loading buffer plus $1 \mathrm{mM}$ DTT. Samples were heated at $90^{\circ} \mathrm{C}$ for $5 \mathrm{~min}$ and subsequently analysed by SDS-PAGE followed by autoradiography.

Subcloning of truncated Atg5. For transduction of cells and the production of recombinant protein, the predicted cDNA of truncated Atg 5 was cloned into pcDNA3 vector (Invitrogen), HIV-derived vector pWPT (gift from D. Trono, Swiss Institute of Technology (EFPL), Lausanne, Switzerland), pEGFP-N1 vector (Clontech, St-Germain-en-Laye, France) and pET-15b plasmid. The end sequence of truncated Atg 5 was recognized by the following primer sequence: 5'-TCACGTTGTCTGATATATTCTAAAG-3' (the underlined sequence represents an artificially introduced stop codon).

Lentiviral gene transfer. Full-length and truncated Atg5 were subcloned into the HIV-derived vector pWPT, which contains a cytomegalovirus (CMV) promoter ${ }^{32}$. Stable Atg5 gene silencing was performed using PLVTHM (gift from D. Trono), a lentiviral vector for siRNA delivery ${ }^{33}$. Oligonucleotides suitable for siRNA experiments were designed against the mouse Atg5 sequence ${ }^{5}$. The calpain-resistant $A \operatorname{tg} 5^{\Delta 191-196}$ was generated using QuikChange site-directed mutagenesis kit (Stratagene Europe, Amsterdam, The Netherlands). To downregulate the small subunit of calpain (NM_001749) in HeLa cells, calpain-specific siRNAs in pLKO.1-puro were obtained from Sigma. For more information, please see Supplementary Information, Methods.

Confocal laser scanning microscopy. Cytospins were made from neutrophils on non-coated slides ${ }^{12}$. HeLa cells were allowed to grow overnight on washed coverslips. Indirect immunostainings for Atg5 and VDAC were performed at $4{ }^{\circ} \mathrm{C}$ overnight by using the following primary antibodies: Anti-Atg5 (1:100; diluted in blocking buffer) and anti-VDAC monoclonal antibody (1:50). Incubation with appropriate TRITC- and FITC-conjugated secondary antibodies (Jackson ImmunoResearch Laboratories, Milan Analytica, La Roche, Switzerland) was performed in the dark at room temperature for $1 \mathrm{~h}$. The slides were analysed by confocal microscopy (LSM 510, Carl Zeiss, Heidelberg, Germany). The scale bars shown in each photograph represent $10 \mu \mathrm{M}$.
For colocalization studies, unprocessed, unfiltered and undeconvoluted data sets were analysed using the Imaris software (Bitplane AG, Zurich, Switzerland), considering every singular layer of a stack separately. Quantitative data of colocalization events were determined by the statistics modules in the colocalization and Voxelshop software of the Imaris package. Intensities were given as sum of all colocalizing voxels in a data set and a computer image was generated. For quantitative analysis of colocalization, the Pearson's correlation coefficient was calculated ${ }^{34}$.

Analysis of the mitochondrial release of cytochrome $c$ in vitro. Mitochondria were freshly isolated from the liver of 2-month-old mice ${ }^{35}$. Briefly, isolated mitochondria were incubated with $0.5 \mu \mathrm{M}$ recombinant Bax and tBid, as well as with the indicated concentrations of the $24 \mathrm{~K}$ and $33 \mathrm{~K}$ forms of Atg5 at $37^{\circ} \mathrm{C}$ for $1 \mathrm{~h}$. After centrifugation at $20,000 \mathrm{~g}$ for $15 \mathrm{~min}$, the supernatants were analysed for the presence of cytochrome $c$ by immunoblotting. To exclude the possibility of mitochondrial damage during isolation, the supernatant was also analysed after centrifugation of the mitochondria but before their incubation with recombinant proteins. Mitochondrial pellets were resuspended in lysis buffer and were additionally analysed by immunoblotting.

Statistical analysis. An analysis of variance test and Student's $t$-test were used to compare mean levels. $P<0.05$ was considered statistical significant.

Note: Supplementary Information is available on the Nature Cell Biology website.

\section{ACKNOWLEDGMENTS}

This work was supported by the Swiss National Science Foundation (grant No. 310000-107526 and 310000-112078).

\section{COMPETING FINANCIAL INTERESTS}

The authors declare that they have no competing financial interests.

Published online at http://www.nature.com/naturecellbiology/

Reprints and permissions information is available online at http://npg.nature.com/ reprintsandpermissions/

1. Levine, B. \& Klionsky, D. J. Development by self-digestion: Molecular mechanisms and biological functions of autophagy. Dev. Cell 6, 463-477 (2004).

2. Gozuacik, D. \& Kimchi, A. Autophagy as a cell death and tumor suppressor mechanism. Oncogene 23, 2891-2906 (2004).

3. Blommaart, E. F., Luiken, J. J. \& Meijer, A. J. Autophagic proteolysis: control and specificity. Histochem. J. 29, 365-385 (1997).

4. Yu, L. et al. Regulation of an ATG7-beclin 1 program of autophagic cell death by caspase-8. Science 304, 1500-1502 (2004).

5. Shimizu, $\mathrm{S}$. et al. Role of $\mathrm{BCl}-2$ family proteins in a non-apoptotic programmed cell death dependent on autophagy genes. Nature Cell Biol. 6, 1221-1228 (2004).

6. Mizushima, N. et al. Dissection of autophagosome formation using Apg5-deficient mouse embryonic stem cells. J. Cell. Biol. 152, 657-667 (2001).

7. Qu, X. et al. Promotion of tumorigenesis by heterozygous disruption of the beclin 1 gene. J. Clin. Invest. 112, 1809-1820 (2003).

8. Yue, Z., Jin, S., Yang, C., Levine, A. J. \& Heintz, N. Beclin 1, an autophagy gene essential for early embryonic development, is a haploinsufficient tumor suppressor. Proc. Natl Acad. Sci. USA 100, 15077-15082 (2003).

9. Goldstein, J. C., Waterhouse, N. J., J uin, P., Evan, G. I. \& Green, D. R. The coordinate release of cytochrome $\mathrm{c}$ during apoptosis is rapid, complete and kinetically invariant. Nature Cell Biol. 2, 156-162 (2000).

10. Simon, H.-U. Neutrophil apoptosis pathways and their modifications in inflammation. Immunol. Rev. 193, 101-110 (2003).

11. Gao, G. \& Dou, Q. P. N-terminal cleavage of Bax by calpain generates a potent proapoptotic 18-kDa fragment that promotes $\mathrm{BCl}-2$-independent cytochrome $\mathrm{c}$ release and apoptotic cell death. J. Cell Biochem. 80, 53-72 (2000).

12. Altznauer, F., Conus, S., Cavalli, A., Folkers, G. \& Simon, H.-U. Calpain-1 regulates Bax and subsequent Smac-dependent caspase-3 activation in neutrophil apoptosis. J. Biol. Chem. 279, 5947-5957 (2004).

13. Arthur, J. S., Elce, J. S., Hegadorn, C., Williams, K. \& Greer, P. A. Disruption of the murine cal pain small subunit gene, Capn4: calpain is essential for embryonic development but not for cell growth and division. Mol. Cell. Biol. 20, 4474-4481 (2000).

14. Martin, S. J. et al. Early redistribution of plasma membrane phosphatidylserine is a general feature of apoptosis regardless of the initiating stimulus: Inhibition by overexpression of BCl-2 and Abl. J. Exp. Med. 182, 1545-1556 (1995).

15. Strasser, A. The role of B $\mathrm{B} 3$-only proteins in the immune system. Nature Rev. Immunol. 5, 189-200 (2005)

16. Marchenko, N. D., Zaika, A. \& Moll, U. M. Death signal-induced localization of p53 protein to mitochondria: A potential role in apoptotic signaling. J. Biol. Chem. 275, 16202-16212 (2000)

17. Mihara, M. et al. p53 has a direct apoptogenic role at the mitochondria. Mol. Cell 11, 577-590 (2003).

18. Chipuk, J. E. et al. Direct activation of Bax by $\mathrm{p} 53$ mediates mitochondrial membrane permeabilization and apoptosis. Science 303, 1010-1014 (2004). 
19. Leu, J. I., Dumont, P., Hafey, M., Murphy, M. E. \& George, D. L. Mitochondrial p53 activates Bak and causes disruption of a Bak-Mcl1 complex. Nature Cell Biol. 6, 443-450 (2004).

20. Li, H. et al. Cytochrome c release and apoptosis induced by mitochondrial targeting of nuclear orphan receptor TR3. Science 289, 1159-1164 (2000).

21. Karuman, P. et al. The Peutz-J egher gene product LKB1 is a mediator of p53-dependent cell death. Mol. Cell 7, 1307-1319 (2001)

22. Chua, B. T. et al. Mitochondrial translocation of cofilin is an early step in apoptosis induction. Nature Cell Biol. 5, 1083-1089 (2003).

23. Daigle, I., Yousefi, S., Colonna, M., Green, D. R. \& Simon, H.-U. Death receptors bind SHP-1 and block cytokine-induced anti-apoptotic signaling in neutrophils. Nature Med. 8, 61-67 (2002).

24. Simon, H.-U. et al. Eosinophils maintain their capacity to signal and release eosinophil cationic protein upon repetitive stimulation with the same agonist. J. Immunol. 165, 4069-4075 (2000)

25. Altznauer, F. et al. Inflammation-associated cell cycle-independent block of apoptosis by survivin in terminally differentiated neutrophils. J. Exp. Med. 199, 1343-1354 (2004).

26. Martinelli, S. et al. Induction of genes mediating interferon-dependent extracellular trap formation during neutrophil differentiation. I. Biol. Chem. 279, 44123-44132 (2004).

27. Adrain, C., Creagh, E. M. \& Martin, S. J. Apoptosis-associated release of Smac/DIABLO from mitochondria requires active caspases and is blocked by $\mathrm{BCl}-2$. EMBO J. 20, 6627-6636 (2001)
28. Yousefi, S., Green, D. R., Blaser, K. \& Simon, H.-U. Protein-tyrosine phosphorylation regulates apoptosis in human eosinophils and neutrophils. Proc. Natl Acad. Sci. USA 91, 10868-10872 (1994).

29. von Gunten, S. et al. Siglec-9 transduces apoptotic and nonapoptotic death signals into neutrophils depending on the proinflammatory cytokine environment. Blood 106, 1423-1431 (2005).

30. Takeuchi, H., Kanzawa, T., Kondo, Y. \& Kondo, S. Inhibition of platelet-derived growth factor signalling induces autophagy in malignant glioma cells. Br. J. Cancer 90, 10691075 (2004)

31. Wolf, B. B. et al. Calpain functions in a caspase-independent manner to promote apoptosis-like events during platelet activation. Blood 94, 1683-1692 (1999).

32. Bovia, F. et al. Efficient transduction of primary human B lymphocytes and nondividing myeloma B cells with HIV-1-derived lentiviral vectors. Blood 101, 1727-1733 (2003).

33. Wiznerowicz, M. \& Trono D. Conditional suppression of cellular genes: lentivirus vector-mediated drug-inducible RNA interference. J. Virol. 77, 8957-8961 (2003).

34. Costes, S. V. et al. Automatic and quantitative measurement of protein-protein colocalization in live cells. Biophys. J. 86, 3993-4003 (2004).

35. Uren, R. T. et al. Mitochondrial release of pro-apoptotic proteins: electrostatic interactions can hold cytochrome $\mathrm{c}$ but not Smac/DIABLO to mitochondrial membranes. J. Biol. Chem. 280, 2266-2274 (2005). 


\section{Supplementary Information}

a
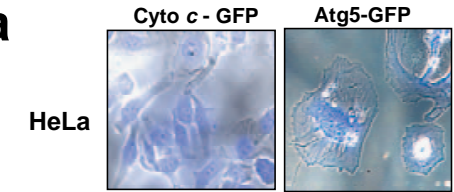

GFP

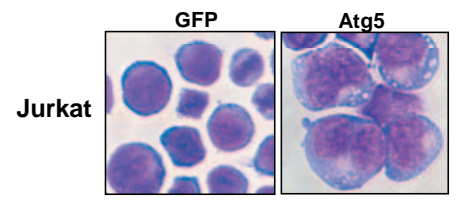

b

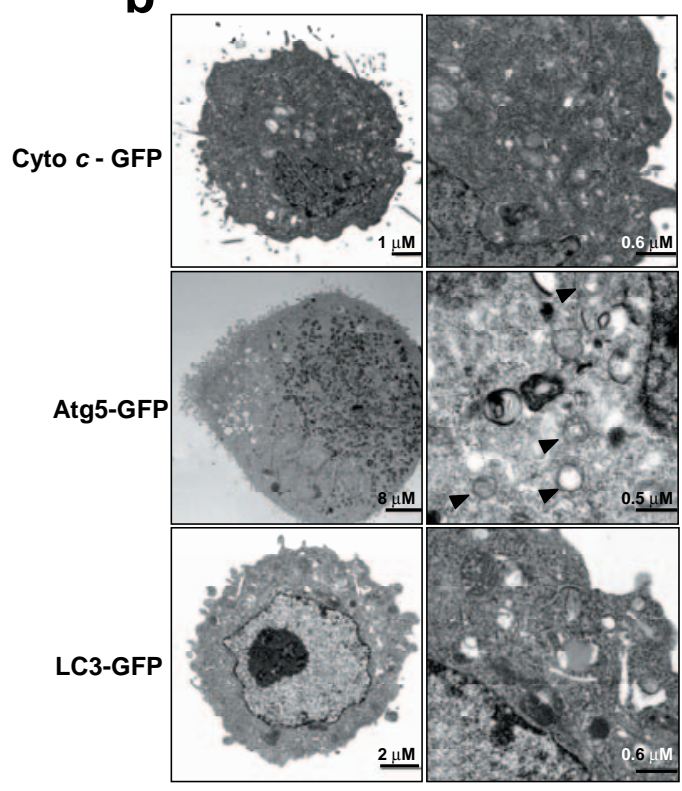

C
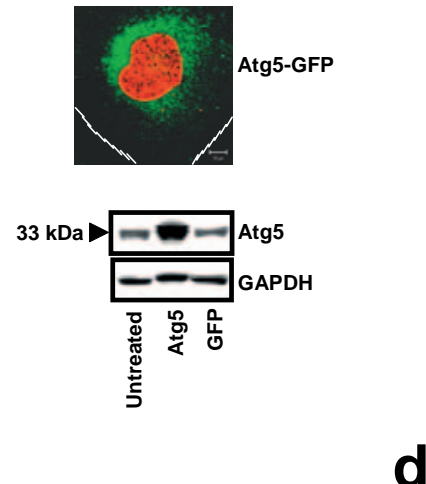

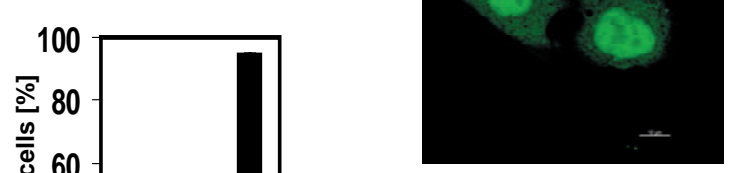

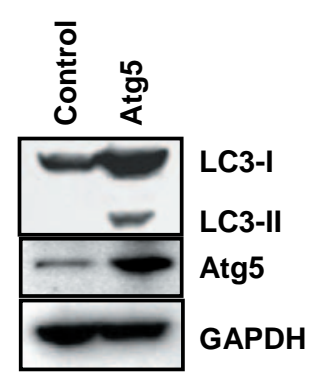

HeLa

LC3-GFP
Control

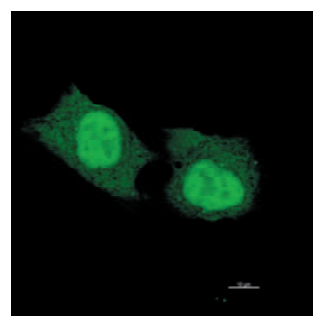

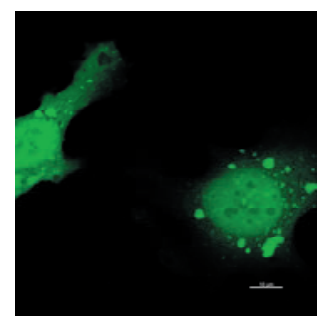

Atg5
Figure S1 Enforced expression of Atg5 promotes autophagy. a, HeLa cells were stably transfected with GFP-tagged Atg5 (upper panel) and J urkat with Atg5 (lower panel). HeLa cells were analyzed following Hoechst staining by overlaying phase contrast and fluorescence images. J urkat cells were analyzed following Diff-Quik staining and regular light microscopy. Atg5-overexpressing cells increased their size and shape, and demonstrated evidence for vacuolization. Atg5 expression was controlled by confocal microscopy and immunoblotting, respectively (right panels). The nucleus in the upper right panel was stained with propidium iodide. The white lines indicate the border between the intracellular and the extracellular space that was visible at a larger magnification. Bar, $10 \mu \mathrm{M}$. b, Transmission electron microscopy (TEM). HeLa cells stably transfected with GFP-tagged Atg5 were compared with HeLa cells expressing GFP- tagged cytochrome c (cyto c) and GFP-tagged LC3 (Atg8). Enforced expression of Atg5 but not cytochrome $c$ or LC3 resulted in increased cell size and in the appearance of autophagic vacuoles, which were defined as double-membrane vacuolar structures containing cytoplasmic contents (arrow heads). Note that different magnifications were used (bars). Right: Quantitative analysis of Atg5-induced autophagy. Vacuolated cells were defined as having 10 or more autophagic vacuoles by TEM. The percentage of vacuolated HeLa cells dramatically increased following enforced Atg5 expression. c, Immunoblotting. In GFP-LC3 labeled cells overexpressing Atg5, LC3-II, indicative for autophagosome formation, was detected. d, Confocal microscopy. In control cells, LC3 shows a cytoplasmic distribution. Following enforced Atg5 expression, GFP-LC3 showed punctate staining, which may represent LC3-II. 

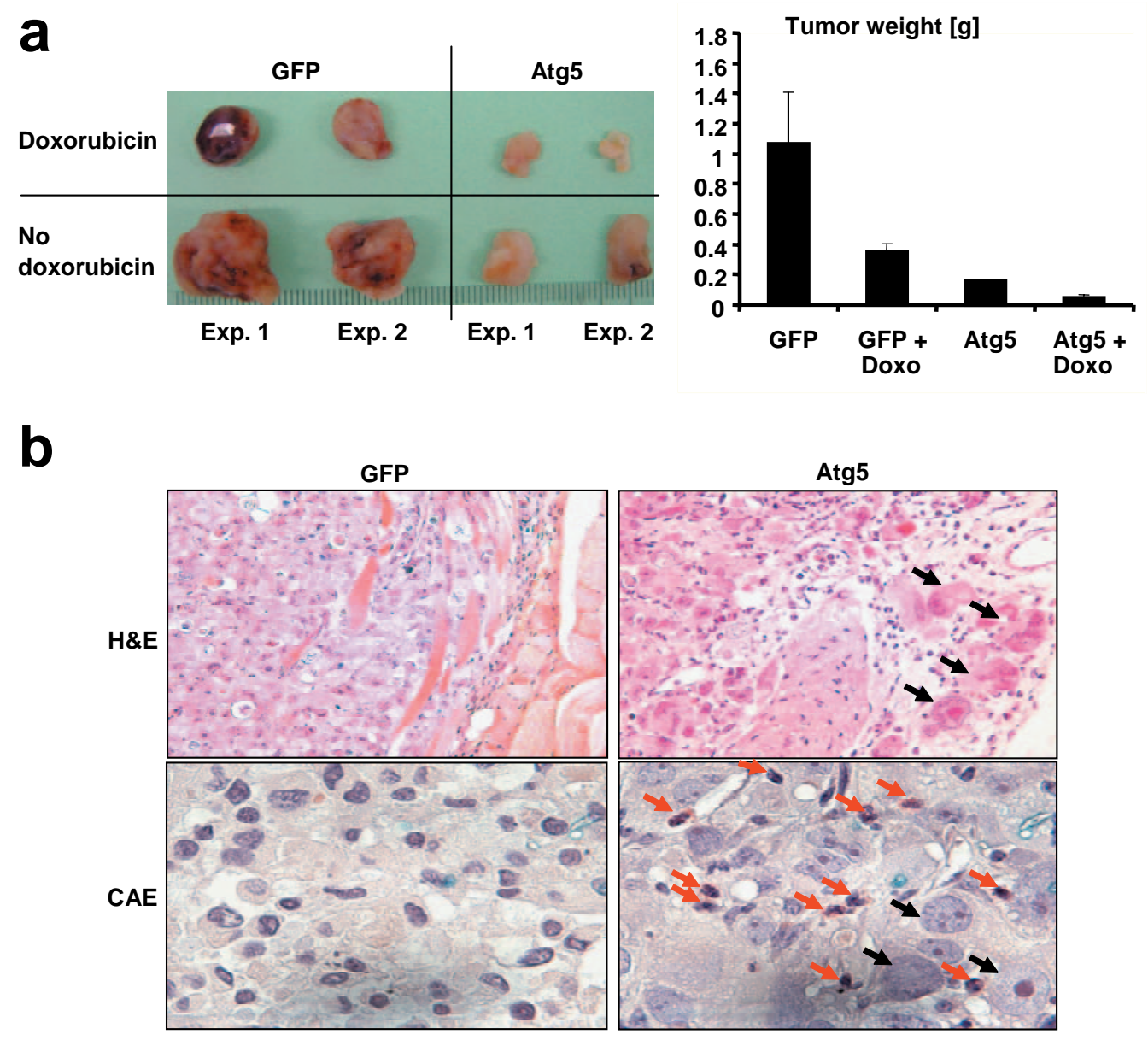

Figure $\mathbf{S 2}$ Atg5 inhibits tumor growth and increases efficacy of anticancer drugs in vivo. MDA-MA-231 cells with normal and enforced Atg5 expression were implanted in nude mice and the tumors were analyzed 18 days later. a, Left panel: Photographs of explanted tumors. Right panel: Tumor weights of explanted tumors (means \pm S.E.M of two independent experiments).
Almost no tumor growth was seen in mice that received Atg5 overexpressing tumors and doxorubicin (Doxo) treatment. b, Histological analysis. Atg5 overexpressing tumors exhibited increased cell size and vacuolization (black arrows) as well as neutrophil infiltration (red arrows). 
a

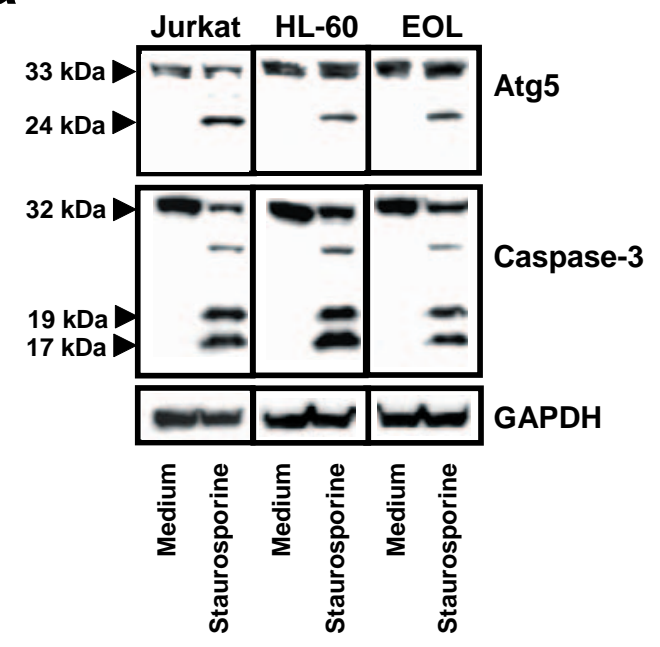

b

\section{Eosinophils}

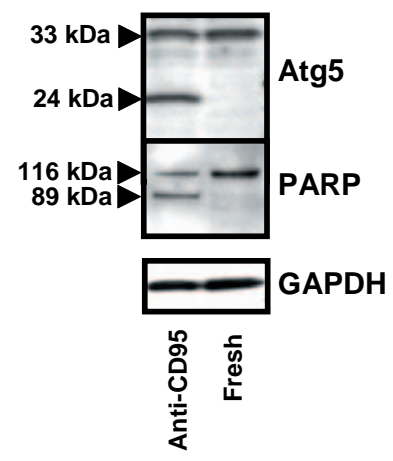

Figure S3 Apoptosis is associated with Atg5 cleavage as assessed by immunoblotting. a, Staurosporine-induced apoptosis (5-h treatment) in cells of different lineages. Apoptosis was associated with the appearance of a 24-kDa anti-Atg5-reactive protein. Blots were stripped and reprobed with anti-caspase-3 antibody, demonstrating evidence for staurosporine-induced caspase-3 activation. b, Anti-CD95-induced apoptosis (5-h treatment) of blood eosinophils. Apoptosis was associated with the appearance of a 24-kDa anti-Atg5-reactive protein and PARP cleavage, indicating caspase activation. 


\section{SUPPLEMENTARY INFORMATION}

\section{ATG5 GENE TRANSFER RESULTS IN INCREASED AUTOPHAGY}

As analyzed by light microscopy, Atg5 overexpressing cells increased their cellular size. Moreover, the HeLa cells became more flat and in Jurkat cells, we observed vacuole-like structures. Atg5 was seen in the cytoplasm, mostly in the perinuclear area as determined by fluorescence analysis (Fig. S1a). In addition, we analyzed these cells by transmission electron microscopy. Atg5 but not LC3 or cytochrome $c$ overexpression resulted in a dramatic increase of double membrane vacuolar structures containing visible cytoplasmic contents ${ }^{1,2}$ and of the cell size (FEBS Letters 2006; 580: 2623) both characteristic features of autophagy (Fig. S1b).

LC3 is considered as a biomarker for autophagy (EMBO J. 2000; 19: 5720 and Mol. Biol. Cell 2004; 15: 1101). To further demonstrate that Atg5 indeed induces autophagy, we overexpressed GFP-LC3 in the presence and absence of concurrent Atg5 overexpression in HeLa cells. Immunoblot analysis using anti-GFP antibody revealed that Atg5 overexpression was associated with the conversion of cytosolic LC3-I into the autophagosome-specific isoform LC3-II (Fig. S1c). Moreover, Atg5 overexpression resulted in multiple GFP-LC3 dots, whereas control cells showed a diffuse LC3 expression pattern (Fig. S1d). Both the generation of LC3-II and the appearance of punctate GFP-LC3 are accepted methods for monitoring autophagy (EMBO J. 2000; 19: 5720 and Mol. Biol. Cell 2004; 15: 1101). Taken together, isolated exogenous Atg5 gene transfer resulted in cells exhibiting signs of increased autophagy. 


\section{ANTICANCER EFFECT OF ATG5 IN VIVO}

Since Atg5 expression appeared to correlate with the susceptibility of cells to undergo anticancer drug-mediated apoptosis in vitro (see Fig. 1), we asked whether the new insight linking autophagy with apoptosis could be translated into a new strategy for the treatment of cancer under in vivo conditions. Breast cancer cells expressing endogenous and increased levels of Atg5 were subcutaneously injected in immunodeficient nude mice and tumor growth was observed in the presence and absence of doxorubicin therapy over a time period of 18 days. Within this time period, no death occurred due to the cancer or the drug treatment. Tumor growth was analyzed by measuring the tumor weight after sacrificing the mice at day 18 . Doxorubicin induced growth inhibition of approximately 65\%. Strikingly, Atg5 overexpression alone reduced tumor growth by approximately $83 \%$. The combination of Atg5 overexpression and doxorubicin treatment did almost completely block tumor growth (approximate inhibition was 95\%) (Fig. S2a). The histological analysis of the tumors demonstrated, besides high frequency of apoptosis/necrosis, increased size and some vacuolization of the remaining cancer cells that received the Atg5 gene (Fig. S2b), confirming the morphological characteristics noticed in HeLa and Jurkat cells with enforced Atg5 expression under in vitro conditions (Fig. S1). In addition, we observed large neutrophil infiltration associated with the implantation of cancer cells expressing high levels of Atg5. Neutrophil infiltration became particularly obvious when sections were stained with chloroacetate esterase (CAE) (Fig. S2b). 


\section{SUPPLEMENTARY INFORMATION METHODS}

Reagents. GM-CSF was from Novartis Pharma GmbH (Nürnberg, Germany). Staurosporine and recombinant tBid were obtained from Apotech (distributed by Alexis Biochemicals, Lausen, Switzerland). Recombinant caspases -3, -6, -7, -8 and

-9 were from Alexis Biochemicals. Enzymatically active calpain-1, calpain-2, cathepsin $B$, and cathepsin D, as well as calpastatin-derived peptide and ALLN were obtained from Calbiochem-Novabiochem Corp. (distributed by Juro Supply GmbH,

Lucerne, Switzerland). (L)-3-carboxy-trans-2,3-epoxypropionyl-leu-amido-(4guanidino-)butane-ethylester (E64-d) and all other chemicals were, unless stated otherwise, from Sigma (Buchs, Switzerland).

Production of recombinant Atg5 and polyclonal anti-human Atg5 antibody. The Atg5 cDNA was obtained by RT-PCR using cDNA from HeLa cells. Primers were designed based on the published sequence (NCBI, Acc \#12803724) and synthesized by MWG-Biotech AG, Ebersberg, Germany). Sequences were as follows: 5'-CGG GAT CCA TGA CAG ATG ACA AAG ATG TGC-3' and 5'-GGA AGC TTT CAA TCT GTT GGC TGT GGG-3'. These primers included restriction sites (underlined). The PCR-product was subcloned into pQE-30 with a [His]6-affinity tag (Qiagen, Basel, Switzerland). The Atg5 sequence was confirmed by sequence analysis. Recombinant Atg5 was produced and purified using Nickel column chromatography. Polyclonal rabbit antisera were raised against purified [His]6-Atg5 fusion protein. The production of anti-Atg5 antibodies was controlled by immunoblotting using [His] $]_{6}-\mathrm{Atg} 5$ and unrelated $[\mathrm{His}]_{6}-$ fusion proteins. 
Cell lines. Jurkat, HeLa, HL-60, and MDA-MB-231 cells were obtained from American Type Culture Collection (ATCC, Rockville, MD, USA). CEM cells overexpressing $\mathrm{Bcl}-2^{14}$ as well as control CEM cells were from Dr. S. Martin (Dublin, Ireland). HeLa cells expressing cytochrome-c-GFP ${ }^{9}$ were provided by Dr. D. R. Green (San Diego, CA, USA). All cells except HeLa, HL-60, and MDA-MB-231 cells were grown in RPMI 1640 with 10\% heat-inactivated fetal calf serum (complete culture medium, Life Technologies, Basel, Switzerland). HeLa and MDA-MB-231 cells were grown in DMEM medium and HL-60 cells in ISCOVE medium (both Life Technologies) supplemented with $5 \%$ heat-inactivated fetal calf serum. All cell lines were maintained by serial passage and used in their logarithmic growth phase.

Transmission electron microscopy. Cells $\left(1 \times 10^{6}\right)$ were resuspended in $1 \mathrm{ml}$ of $2.5 \%$ phosphate-buffered glutaraldehyde at $4^{\circ} \mathrm{C}$. They were then washed with PBS and postfixed with $1 \% \mathrm{OsO}_{4}$ for $1.5 \mathrm{~h}$ at room temperature. Cell blocks were then embedded in Spurr's low viscosity resin (Electron Microscopy Sciences, Hatfield, PA, USA). Grey thin sections were contrasted with uranylacetate and lead citrate. Cells were observed with an electron microscope (Zeiss EM 10 C, Oberkochen, Germany), and 20 to 30 cells were photographed per sample.

Human tumor xenograft model. Unmodified, GFP- and Atg5-overexpressing human breast cancer MDA-MA-231 cells $\left(5 \times 10^{6}\right)$ were implanted in the dorsal subcutis of athymic female nude mice (Harlan, Horst, Netherlands). When the tumors were between $40-50 \mathrm{~mm}^{3}$, each group of animals was pair matched into doxorubicin treatment and control subgroups. Tumor measurements were taken by callipers and converted to tumor volume $(V)$ using the formula $\left(V=W^{2} \times L / 2\right)$, where 
$W$ and $L$ are the smaller and larger diameters, respectively. Doxorubicin $(10 \mathrm{mg} / \mathrm{kg}$ bodyweight; Adriblastin ${ }^{\circledR}$, Pfizer AG, Zurich, Switzerland) was administered via i.p. on the day of pair matching, on day 7 , and on day 14 . On day 18 , mice were sacrificed and the tumors were explanted and subsequently weighed and histologically analyzed. The animal experiments were conducted according to the guidelines of the State of Bern, Switzerland.

In vitro transcription and translation. $0.5 \mu \mathrm{g}$ of purified plasmids ( $\mathrm{EET}-15 \mathrm{~b}$, Novagen, distributed by VWR International, Lucerne, Switzerland) containing sequence verified cDNAs encoding full-length Atg5, truncated Atg5, or del 191-196 Atg5 (see below), as well as Bid (vector was kindly provided by Dr. K. SchulzeOsthoff, Düsseldorf, Germany) were in vitro-transcribed and translated using a coupled transcription/translation TNT kit (Promega, Catalys AG, Wallisellen, Switzerland) according to manufacturer`s instructions.

Identification of the calpain cleavage site. Recombinant Atg5 was produced by cloning the Atg5 cDNA into pET-15b expression vector using the following primer sequences: 5'-GCA GCE ATA TGA CAG ATG ACA AAG ATG TGC-3' and 5'-CAG CCG GAT CCT CAA TCT GTT GGC TGT GGG-3' (underlined sequences represent Ndel and BamHI restriction sites). The Atg5 sequence was confirmed by sequencing. Atg5 was expressed in Terrific broth at $20^{\circ} \mathrm{C}$ using BL21(DE3) Codon ${ }^{+}-\mathrm{RIL}$ cells. Recombinant Atg5 was isolated and purified by Nickel column chromatography. Fractions containing the protein were collected and digested with thrombin to remove the $[\mathrm{His}]_{6}$-tag. Protein quality was assessed by SDS-PAGE, and concentrations were calculated by amino acid analysis. 
Calpain digestion of Atg5 was essentially performed as described before ${ }^{31}$. Samples for Edman sequencing were prepared by blotting the separated cleavage products onto PVDF membranes and cutting out the bands corresponding to the fragments of interest. Fragments for mass spectrometry were isolated by HPLC. Edman sequencing and mass spectrometry were performed at the Protein Service Laboratory of the Institute of Molecular \& Biophysics at the Swiss Federal Institute of Technology (Zurich) on a fee-for-service basis.

Transient transfection of cells. Full-length and truncated Atg5 were subcloned into pcDNA3 vector. HeLa cells $\left(1 \times 10^{5}\right.$ cells $)$ were transfected in six-well plates using Lipofectamine $^{\mathrm{TM}} 2000$ (Invitrogen). Cells were morphologically analyzed $24 \mathrm{~h}$ later following Hoechst staining using a fluorescence microscope. Co-transfection of PCMV $\beta$-galactosidase was used to normalize the transfection efficiencies in these experiments.

Lentiviral gene transfer. Full-length and truncated Atg5 were subcloned into the HIV-derived vector pWPT, which contains a cytomegalovirus (CMV) promoter $^{32}$. Recombinant viruses were produced by calcium transfection together with the envelope vector pMD.G and the packaging vector pCMVR8.91 (all provided by Dr. D. Trono, University of Geneva, Switzerland) into 293T cells. In parallel experiments, pWPT containing GFP was produced and used for control experiments. The supernatants were collected after $24 \mathrm{~h}$ and $48 \mathrm{~h}$, cleared by low-speed centrifugation (2000 rpm for $10 \mathrm{~min}$ ), filtered through $0.22 \mu \mathrm{M}$ filter (Millipore AG, Volketswil, Switzerland), and immediately added to immature neutrophils, HeLa, Jurkat, CEM, and MDA-MB-231 cells. The expression of Atg5 and its cleavage product after 
transduction $(24 \mathrm{~h})$ was controlled by immunoblotting. The efficacy of gene transfer was also controlled by counting GFP positive cells following pWPT-GFP transduction and was usually $100 \%$. For analyzing autophagy by immunoblotting and confocal microscopy, cells were transfected with LC3-GFP, which we subcloned into pWPT.

Stable Atg5 gene silencing was performed using pLVTHM (gift of Dr. D. Trono, Geneva, Switzerland), a lentiviral vector for siRNA delivery ${ }^{33}$. Oligonucleotides suitable for siRNA experiments have been designed according to the mouse Atg5 sequence $^{5}$. To generate the template for human $\operatorname{Atg} 5$ siRNA, we used the corresponding human sequences and incorporated them in a short hairpin structure, using the stem loop sequence 5'-TTC AAG AGA-3'. The following annealed primers were used for ligation: 5' - CGC GTC CCC AAC TTG TTT CAC GCT ATA TCA TTC AAG AGA TGA TAT AGC GTG AAA CAA GTT TTT TTG GAA AT - 3' and 5' - CGA TTT CCA AAA AAA CTT GTT TCA CGC TAT ATC ATC TCT TGA ATG ATA TAG CGT GAA ACA AGT TGG GGA - 3' (reverse sequence). Both primers were phosphorylated on both sites. After annealing, Atg5 siRNA was directly cloned into pLVTHM using Mlul and Clal restriction sites. The Atg5 siRNA construct was verified by sequence analysis. Virus production was performed as described above. Following transduction, usually $100 \%$ were GFP positive and silencing of the Atg5 gene was controlled by immunoblotting.

The calpain-resistant Atg5 ( $\left.{ }^{\text {del }} 191-196\right)$ was generated using QuikChange Site-Directed Mutagenesis Kit (Stratagene Europe, Amsterdam, The Netherlands) along with the following primers: forward, 5' - CGT TAT ATC CCC TTT AGA ATA TAT CCT TTC ATT CAG AAG CTG TTT CG - 3'; reverse, 5' - CGA AAC AGC TTC TGA ATG AAA GGA TAT ATT CTA AAG GGG ATA TAA CG - 3'. The construct was subjected to DNA sequencing to ensure accuracy and lentiviral gene transfer was 
performed using pWPT. To downregulate the small subunit of calpain (NM_001749) in HeLa cells, we obtained calpain-specific siRNAs (5' - CGC ACA CAT TAC TCC AAC ATT - 3' and 5' - CGC CAC AGA ACT CAT GAA CAT - 3') in pLKO.1-puro from Sigma. For controls, we used non-targeted siRNA with the following sequence: 5' - CAA CAA GAT GAA GAG CAC CAA - 3'. Gene silencing was again controlled by immunoblotting.

Stable transfection of cells. HeLa cells were transfected with full-length Atg5 in pEGFP-N1 vector (Clontech, Becton Dickinson Biosciences) by calcium phosphate precipitation. G418 resistant clones were screened for GFP expression using flow cytometry and fluorescence microscopy. Expression of Atg5 was additionally controlled by immunoblotting. The obtained clones were used for functional studies as well as size controls in the immunoblotting experiments.

Immunoprecipitation. Cells $\left(1 \times 10^{7}\right)$ were washed with PBS and buffer A (50 mM Hepes, pH 7.2, $143 \mathrm{mM} \mathrm{KCl}, 5 \mathrm{mM} \mathrm{MgCl}$, $1 \mathrm{mM}$ EGTA, phosphatases and proteases inhibitors), and then lysed in buffer A plus $0.2 \%$ NP-40 on ice for $30 \mathrm{~min}$. Cell lysates were passed 10-15 times through a 26-gauge needle, centrifuged, and precleared with $100 \mu \mathrm{l}$ of $50 \%$ protein A-sepharose (Sigma) at $4^{\circ} \mathrm{C}$ for $1 \mathrm{~h}$. Immunoprecipitations were performed using $5 \mu$ of affinity-purified rabbit anti-human Bax and Bcl- $\mathrm{x}_{\mathrm{L}} \mathrm{S} 18$ antibodies (both Santa Cruz Biotechnology, Inc., distributed by LabForce) in the presence of $2.5 \mathrm{mg} / \mathrm{ml}$ ovalbumine at $4^{\circ} \mathrm{C}$ for $2 \mathrm{~h}$. Fifty $\mu \mathrm{l}$ of a $50 \%$ protein A-sepharose suspension were added and the immune complexes captured on a rotating wheel at $4^{\circ} \mathrm{C}$ for $90 \mathrm{~min}$. Immunocomplexes were washed three times in 
buffer $\mathrm{A}$ and boiled at $95^{\circ} \mathrm{C}$ for 5 min before loading on $12 \%$ NuPage gels (Invitrogen AG, Basel, Switzerland).

Analysis of the mitochondrial release of cytochrome $c$ in intact cells. To assess the status of cytochrome $c$ release from individual cells, HeLa cells were grown on coverslips and loaded with $500 \mathrm{nM}$ Mitotracker orange (Molecular Probes) at $37^{\circ} \mathrm{C}$ for $10 \mathrm{~min}$. Cells were subsequently fixed with $4 \%$ paraformaldehyde solution and then immunostained with anti-cytochrome $c$ monoclonal antibody (1/100). Staining of the primary monoclonal antibody was visualized by incubation with FITC-conjugated secondary antibody, and slides were analyzed by confocal laser scanning microscopy (LSM 510) $)^{12}$. 